\title{
Temperature Dependence of the Biophysical Mechanisms Underlying the Inhibition and Enhancement Effect of Amiodarone on hERG Channels $\$$
}

\author{
Yung-Chen Lo and (1)Chung-Chin Kuo
}

\author{
Department of Physiology, National Taiwan University College of Medicine, Taipei, Taiwan; and Department of Neurology, \\ National Taiwan University Hospital, Taipei, Taiwan
}

Received February 27, 2019; accepted June 21, 2019

\begin{abstract}
$\mathrm{hERG} \mathrm{K}^{+}$channel is important for controlling the duration of cardiac action potentials. Amiodarone (AMD), a widely prescribed class III antiarrhythmic, could inhibit hERG currents with relatively few tachyarrhythmic adverse events. We use injected Xenopus oocyte with two-electrode voltage clamp techniques to characterize the action of AMD on $h E R G$ channels. We found that AMD binds to the resting $h E R G$ channel with an apparent dissociation constant of $\sim 1.4 \mu \mathrm{M}$, and inhibits $\mathrm{hERG}$ currents at mild and strong depolarization pulses by slowing activation and enhancing inactivation, respectively, at $22^{\circ} \mathrm{C}$. The activation kinetics of hERG channel activation are much faster, but inactivation kinetics are slower at $37^{\circ} \mathrm{C}$. AMD accordingly has a $15 \%$ to $20 \%$ weaker and stronger inhibitory effect at mild and strong depolarization (e.g., -60 and $+30 \mathrm{mV}$, $0.3-$ second pulse), respectively. In the meanwhile, the resurgent hERG tail currents are dose-dependently inhibited by AMD without altering the kinetics of current decay at both $22^{\circ} \mathrm{C}$ and $37^{\circ} \mathrm{C}$, indicating facilitation of recovery from inactivation via the silent route. Most importantly, AMD no longer inhibits but enhances hERG currents at a mild pulse shortly after a prepulse
\end{abstract}

at $37^{\circ} \mathrm{C}$, but not so much at $22^{\circ} \mathrm{C}$. We conclude that $A M D$ is an effective hERG channel-gating modifier capable of lengthening the plateau phase of cardiac action potential (without increasing the chance of afterdepolarization). AMD, however, should be used with caution in hypothermia or the other scenarios that slow hERG channel activation.

\section{SIGNIFICANCE STATEMENT}

It is known that amiodarone (AMD) acts on $\mathrm{hERG} \mathrm{K}^{+}$channels to treat cardiac arrhythmias with relatively little arrhythmogenicity. We found that AMD enhances hERG channel inactivation but slows activation as well as recovery from inactivation, and thus has a differential inhibition and enhancement effect on hERG currents at different phases of membrane voltage changes, especially at $37^{\circ} \mathrm{C}$, but not so much at $22^{\circ} \mathrm{C}$. AMD is therefore a relatively ideal agent against tachyarrhythmia at $37^{\circ} \mathrm{C}$, but should be more cautiously used at lower temperatures or relevant pathophysiological/pharmacological scenarios associated with slower hERG channel activation because of the increased chances of adverse events.

\section{Introduction}

Gating of the hERG $\mathrm{K}^{+}$channel is well known for the acceleration of inactivation over activation during a pulse of strong depolarization (Wang et al., 1997). hERG currents, although based on a depolarization-activated channel, are thus paradoxically decreased at stronger depolarization because more channels are rapidly driven into the inactivation state (Trudeau et al., 1995; Schönherr and Heinemann, 1996; Smith et al., 1996). hERG $\mathrm{K}^{+}$channel gating is also characterized by a large resurgent tail current upon repolarization, presumably signaling recovery from inactivation trespassing an open state. hERG currents would therefore be more inhibited in the presence of more repetitive or prolonged

This work was supported by grants from the Ministry of Science and Technology, Taiwan (MOST) MOST107-2321-B-002-012 (to C.-C.K.) and MOST106-2320-B-002-014-MY3 (to C.-C.K.), and the National Health Research Institute of Taiwan NHRI-EX107-10503NI (to C.-C.K.).

https://doi.org/10.1124/mol.119.116400.

S This article has supplemental material available at molpharm.aspetjournals.org. depolarization. Upon repolarization, resurgent hERG currents presumably are generated to stabilize the resting phase. These characters make hERG channels an important control of appropriate repetitive discharges in heart and many different types of neurons (Babcock and Li, 2013). From the molecular perspective, the basis of the intriguing gating phenomena has been focused on the possibilities of slow activation with relative fast $\mathrm{C}$-type inactivation, such as relocalization of voltage sensor domains or reconfiguration of S-5-P loop on the outer mouth region (Schönherr and Heinemann, 1996; Wang et al., 1997; Torres et al., 2003; Zhang et al., 2004; Jiang et al., 2005), but many of the essential biophysical attributes of gating have remained uncharacterized. For example, hERG channel could recover from inactivation via two routes in theory. Deinactivation before deactivation would necessarily involve trespass of an open state and genesis of currents, and thus the resurgent route. Deactivation before deinactivation, in contrast, would indicate that no open state is trespassed and thus the silent route of recovery, which has been much less characterized (Clancy and Rudy, 2001). Whether there is only 
A
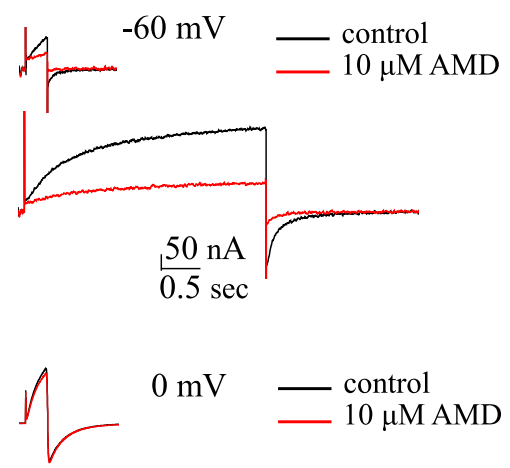

B
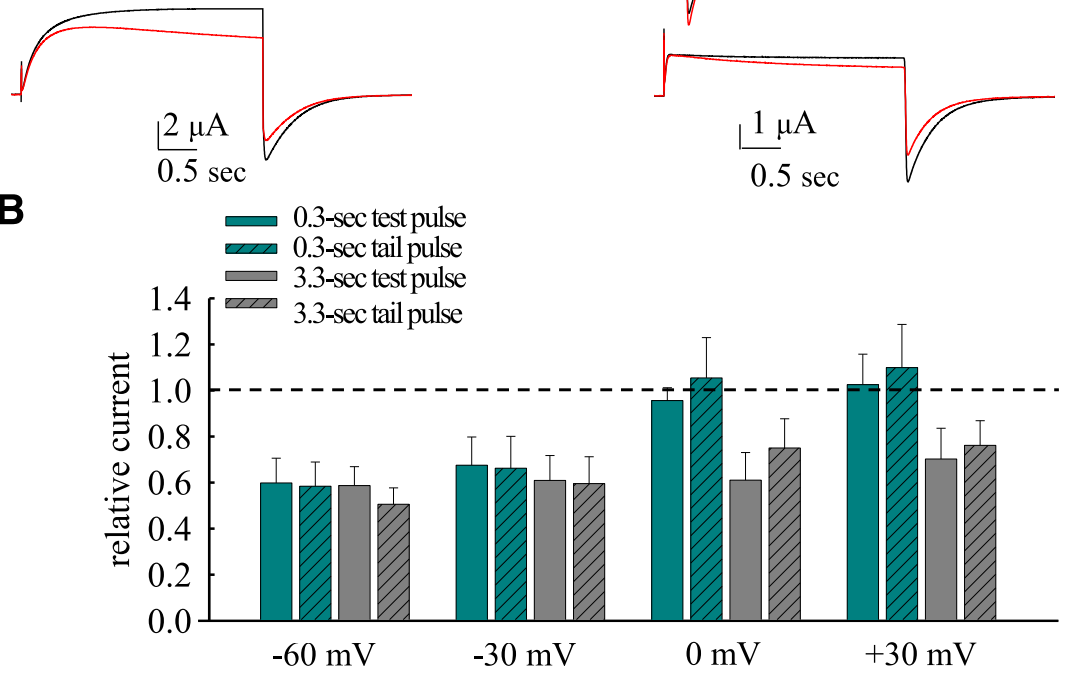

C

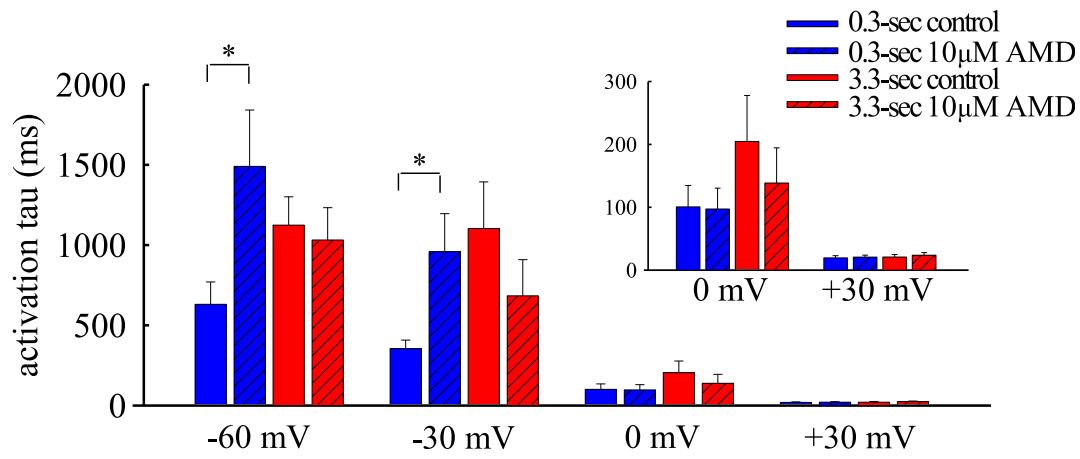

D

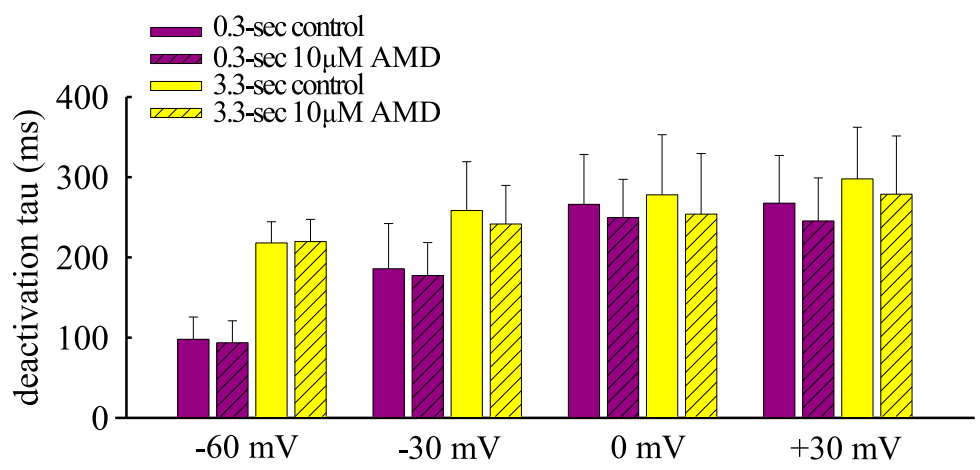

Fig. 1. The voltage-dependent inhibitory effect of AMD on short and long depolarization pulses at $22^{\circ} \mathrm{C}$. (A) hERG currents were elicited by short $(0.3-$ second) and long (3.3-second) test pulses at -60 , $-30,0,+30 \mathrm{mV}$ from a holding potential at -90 $\mathrm{mV}$. (B) The late sustained currents (the average currents in the last $5 \mathrm{~ms}$ of the test pulse) and the peak of tail currents in $10 \mu \mathrm{M}$ AMD are normalized to that in control to give the relative currents in the test and tail pulses ( 0.3 second, green bar; 3.3 seconds, gray bar; $n=10,10,11,10$ for $-60,-30$, $-0,+30 \mathrm{mV}$, respectively). (C) The time constants from the monoexponential fits to the growing phase of the currents (5\% to $95 \%$ of currents) in (A) show that $10 \mu \mathrm{M}$ AMD slows channel activation from holding potential of $(-90 \mathrm{mV})$ at mild pulses (e.g., $-60 \mathrm{mV}$ ) but not strong pulses (e.g., $+30 \mathrm{mV}$ ) (paired two-tailed $t$ test, $* P<0.05$ ). Note this is just an approximate estimate of channel activation kinetics because of the possible contamination by inactivation especially with a longer (3.3-second) pulse. Inset figure: a magnified view of the data at 0 and $+30 \mathrm{mV}$. (D) The time constants from the monoexponential fits to the decay phase of the tail currents (from $5 \%$ to $95 \%$ of the currents) in (A) show that although $10 \mu \mathrm{M}$ AMD has no apparent effect on the deactivation kinetics of hERG currents, more depolarized and prolonged preceding pulses by themselves tend to lead to slower decay (longer time constant or $\tau$ of the decay phase) of the tail currents. The results of different pulse durations are shown in purple ( 0.3 second $)$ and yellow (3.3 seconds), respectively $(n=10,10,11,10$ for $-60,-30,-0,+30 \mathrm{mV}$, respectively). Data of the same test pulse voltages were acquired from the same cells. one open state to be trespassed, and whether and how the different routes of recovery from inactivation are proportioned to determine the size of the resurgent tail currents, are not clear.
Amiodarone (AMD) is the most frequently prescribed type III antiarrhythmic agent (Heger et al., 1981; Zimetbaum, 2007). With prolongation of action potential duration at $90 \%$, 
AMD may prevent re-entrant excitation and thus tachyarrhythmias. The mechanism of action of AMD has been ascribed to inhibition of hERG channel and consequent prolongation of the refractory period, which is a hallmark of the class III antiarrhythmics (Sanguinetti et al., 1995). Interestingly, AMD seems to have a much better safety profile in terms of the risk of induction of severe tachyarrhythmias such as Torsade de Pointes (Roden, 2004). It was proposed that the protonated form of AMD may act as a pore blocker and inhibit hERG channels (Kiehn et al., 1999; Mitcheson et al., 2000; Ridley et al., 2004), and the critical residues involved in AMD inhibition are located at the proximal regions of selectivity filter (Zhang et al., 2016). In contrast, the inactivation-removing mutations such as N588K and N588K/ S631A dramatically reduce the inhibitory effect of AMD (McPate et al., 2008), suggesting that C-type inactivation or gating modification does play an important role in the action of AMD. It is also of note that AMD could enhance rather than inhibit hERG currents at mild depolarization in a prepulse-dependent manner (Furutani et al., 2011). This is incompatible with the idea that AMD acts simply as a pore blocker of hERG channels, but strongly implicates gating modification of hERG channels by AMD. Although a smaller $K_{\mathrm{d}}$ between AMD and hERG channel at $37^{\circ} \mathrm{C}$ than $23^{\circ} \mathrm{C}$ (Kauthale et al., 2015), the action of AMD on the unique gating profiles of hERG channels has not been systemically and fully characterized, especially at $37^{\circ} \mathrm{C}$. We found that AMD binds to the deactivated (closed) state to enhance the voltage dependence of hERG channel gating, and thus inhibits hERG currents at mild depolarization pulses ( -30 to $-60 \mathrm{mV}$ ) but enhances the initial rising phase and then inhibits the late currents due to accelerated inactivation at 0 to $+30 \mathrm{mV}$ at $22^{\circ} \mathrm{C}$. Because of acceleration of activation but slowing of inactivation, the inhibitory effect of AMD at mild and strong depolarization decreases and increases, respectively at $37^{\circ} \mathrm{C}$. Most interestingly, AMD also promotes recovery from inactivation via the silent route to inhibit the resurgent tail currents. The enhancement effect of hERG currents at a premature pulse shortly after a prepulse is also especially prominent at $37^{\circ} \mathrm{C}$. AMD therefore may effectively lengthen the plateau phase of cardiac action potential without increasing the chances of afterdepolarization at $37^{\circ} \mathrm{C}$.

\section{Materials and Methods}

Molecular Biology and Expression of hERG $\mathrm{K}^{+}$Channels. The hERG1-pSP64 cDNA clone was amplified and subsequently extracted from cells by the QIAprep R Spin Miniprep Kit (QIAGEN). The inactivation-removed S620T mutant channel was made with the QuikChange mutagenesis kit (Stratagene, La Jolla, CA) in the wild-type hERG1-pSP64 cDNA plasmid. The point mutation was verified by DNA sequencing. These cDNA plasmids were then cut into linear forms by restriction enzyme (EcoRI) and purified by Gel/polymerase chain reaction DNA (Fragments Extraction Kit, Geneaid). The cDNA templates were used to synthesize cRNA transcripts using mMessage mMachine transcription kit SP6 (Ambion). The hERG cRNA (0.1-1 ng/nl) was then injected into Xenopus oocytes (stages V-VI), which has been previously defolliculated and maintained in the culture medium $(96 \mathrm{NaCl} \mathrm{mM}$, $2 \mathrm{KCl} \mathrm{mM}, 1 \mathrm{CaCl}_{2} \mathrm{mM}, 1 \mathrm{MgCl}_{2 \mathrm{mM}}, 5 \mathrm{HEPES} \mathrm{mM}$, and $50 \mu \mathrm{g} / \mathrm{ml}$ gentamycin, $\mathrm{pH} 7.6$ ) at $14^{\circ} \mathrm{C}$ to $18^{\circ} \mathrm{C}$. The injected Xenopus oocytes were incubated in culture medium 1 to 3 days prior to electrophysiological studies. We have purchased our Xenopus from South Africa, the African Xenopus Facility C.C (+27-443884757; KNYSNA, Western Cape, South Africa).

Electrophysiological Recordings. For recording of macroscopic $\mathrm{K}^{+}$currents, the oocyte was placed in a chamber continuously perfused

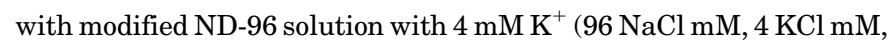
$1 \mathrm{CaCl}_{2} \mathrm{mM}, 1 \mathrm{MgCl}_{2} \mathrm{mM}$, and 5 HEPES mM, pH 7.4). The hERG currents were then recorded with two-microelectrode voltage-clamp method. The voltage-sensing and current-passing electrodes were filled with $3 \mathrm{M} \mathrm{KCl}$ and had a consecutive resistance of 0.1 to $1 \mathrm{M} \Omega$. The membrane potential was controlled by the amplifier (OC-725C; Warner Instrument, Hamden, CT). Data were acquired at room temperature $\left(\sim 22^{\circ} \mathrm{C}\right)$ or $37^{\circ} \mathrm{C}$ using the Digidata-1322A analog/digital interface with pCLAMP software (Axon Instrument, Foster City, CA). The temperature control was achieved by automatic temperature controller (TC-324C; Warner Instrument). The sampling rates were 0.1 to $2 \mathrm{kHz}$. AMD (SigmaAldrich, St. Louis, MO) was dissolved in DMSO to make a $5 \mathrm{mM}$ stock solution and then diluted into the modified ND-96 solution to make final concentration of 0.01 to $100 \mu \mathrm{M}$. The most commonly used $10 \mu \mathrm{M}$ AMD solution contained $0.2 \%$ DMSO, which does not have a significant effect on the hERG currents examined by a step depolarization of $0 \mathrm{mV} \times 30$ seconds from holding potential of $-120 \mathrm{mV}$ (Supplemental Fig. 1). The highest concentration of AMD in this manuscript is $100 \mu \mathrm{M}$. The $2 \%$ DMSO has an enhancement effect on the initial and inhibition effect on the late currents ( $\sim 10 \%$ and $5 \%$, respectively, which should not affect a valid interpretation of the experimental results). The oocyte was always continuously perfused for 10 to 30 minutes before experiments to achieve steady-state distribution of the drug.

Data Analysis. The concentration-response curve is fitted with Hill equation:

$$
\mathrm{I}-\operatorname{Imin} / \operatorname{Imax}-\operatorname{Imin}=1 /[1+[\mathrm{AMD}] / \mathrm{Kd}]^{\mathrm{nH}}
$$

where I is the hERG current in presence of AMD; Imin and Imax are the minimal and maximal hERG current, respectively; [amio] is the concentration of AMD; $K_{\mathrm{d}}$ denotes the apparent affinity of AMD binding to hERG channels; and $\mathrm{nH}$ is the Hill coefficient, which was fixed to 1 . For the monoexponential fitting to the courses that rise to the maximum or decay to the steady-state, the fit functions are of the forms:

$$
\begin{gathered}
I=\mathrm{A} \exp (-\mathrm{t} / \tau)+\mathrm{C}(\text { for the decay phase }) \\
I=\mathrm{A}[1-\exp (-\mathrm{t} / \tau)]+\mathrm{C}(\text { for the rising phase })
\end{gathered}
$$

where $\tau$ is the time constant, A denotes the relative amplitude of the corresponding components, and $\mathrm{C}$ is the steady-state level. For statistical comparison of experimental groups, the Student's $t$ test (paired or nonpaired as designated in the figure legend) is used, and $P<0.05$ is considered to be significant and all statistics are given as mean \pm S.D. All statistical tests had been specified before the experimental results were actually obtained, and all statistical results are reported irrespective of outcome. Basically, all experiments have an independent measurement number $n \geq 4$. All experimental results were verified by at least one complete set of paired data obtained from the same cell. The kinetic model of hERG channel gating is constructed by MATLAB R2015 suite (The Math Works), with Euler method for numeric integration with the time step set at 0.01 to $1 \mathrm{~ms}$. Q-matrix method was employed, and the reversal potential was set to $-84 \mathrm{mV}$.

\section{Results}

AMD Inhibits hERG Currents by Slowing of Activation at Mild Pulses and Enhancement of Inactivation at Strong Pulses at $\mathbf{2 2}^{\circ} \mathrm{C}$. We first explored the effect of AMD at mild to strong, and short to long depolarization pulses (Fig. 1), endeavoring to elucidate the basic gating parameters based on the most simplistic Scheme 1, where C, O, and I stand for the closed, open, and inactivated states, respectively.

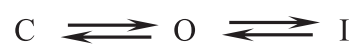

Scheme 1 
The inhibition of hERG currents by $10 \mu \mathrm{M}$ AMD during a short $(\sim 300 \mathrm{~ms})$ test pulse is manifest at a voltage of -60 or $-30 \mathrm{mV}$ at $22^{\circ} \mathrm{C}$, with apparent slowing of the initial activation phase. In contrast, the activation phase is not apparently slowed at strong pulses (e.g., $0 \mathrm{mV}$ and especially $+30 \mathrm{mV}$; Fig. 1, A-C). The tail currents are presumably close to true tails returning from the open to the closed states with a short and weak preceding pulse (e.g., $-60 \mathrm{mV} \times 0.3$ second). A close examination of the kinetics of the decay phase of the tail currents shows that the decay is evidently slower with a $-30 \mathrm{mV}$ than a $-60 \mathrm{mV}$ and with a longer (3.3-second) than a short (0.3-second) test pulse. These slower tail currents therefore are unlikely all true tails returning directly from the open to the closed states. The channel must have significantly entered a third gating state, namely the inactivated state (Scheme 1) with a pulse of $-30 \mathrm{mV} \times 0.3$ second or $-60 \mathrm{mV} \times$ 3.3 seconds, and then giving rise to resurgent tail currents upon recovery from state $\mathrm{I}$ to state $\mathrm{C}$ via state $\mathrm{O}$ at $-90 \mathrm{mV}$. In contrast, the inhibition of hERG currents by $10 \mu \mathrm{M}$ AMD at a test pulse of 0 or $+30 \mathrm{mV}$ is manifest with a pulse length of 3.3 but not 0.3 seconds, suggesting that channel activation is no longer significantly slowed, but inactivation is facilitated by AMD at strong depolarization pulses. We have also examined the effect of AMD with lengthening of the test pulse at -60 to $-30 \mathrm{mV}$ to 120 seconds (Supplemental Fig. 2). The persistence of the inhibitory effect is consistent with the foregoing ideas that a pulse of $-60 \mathrm{mV} \times 3.3$ seconds would already trigger significant channel inactivation and AMD facilitates inactivation. In this regard, it is noted that the time constant of the decay phase of the tail seems to be saturated at $\sim 300 \mathrm{~ms}$ (Fig. 1D; Supplemental Fig. 2), signaling the overall kinetics of dissipation of the open state with the $\mathrm{I}$ to $\mathrm{O}$ and then to $\mathrm{C}$ transition (Fig. 1D; Supplemental Fig. 2). The evident inhibitory effect of AMD, however, is also noted on the tail resurgent currents. This could not be envisaged with just slowed activation and/or facilitated inactivation by AMD. AMD very likely has an additional effect on the genesis of the tail resurgent currents, or the recovery process of the inactivated hERG channels upon repolarization (see below).

The Gating Kinetics of hERG Channels Are Markedly Temperature-Dependent. We then compared the hERG cuurents at $37^{\circ} \mathrm{C}$ and $22^{\circ} \mathrm{C}$ (Fig. 2). It is evident that the currents are activated much faster at $37^{\circ} \mathrm{C}$ than at $22^{\circ} \mathrm{C}$. hERG channel inactivation, however, does not seem to be accelerated or is even apparently abolished, as there is no discernible decay phase in the macroscopic currents at $37^{\circ} \mathrm{C}$. Our data indicate that the biophysical basis of this phenomenon is the slowing of transitions into inactivation (i.e., the $\mathrm{C} \rightarrow \mathrm{I}$ and $\mathrm{O} \rightarrow \mathrm{I}$ transitions at higher temperature of $\left.37^{\circ} \mathrm{C}\right)$. The hERG currents therefore are very much larger at $37^{\circ} \mathrm{C}$ than at $22^{\circ} \mathrm{C}$ during a test pulse of either 0.3 or 3.3 seconds, presumably ascribable to not only acceleration of activation but also slowing of the transitions leading to inactivation. In contrast, the tail currents following a short (0.3-second) pulse to $-60 \mathrm{mV}$ show a much faster decay phase at $37^{\circ} \mathrm{C}$ than at $22^{\circ} \mathrm{C}$ (time constant $\sim 46$ vs. $\sim 138 \mathrm{~ms}$ ). Again, this is probably close to the true tail currents signaling channel deactivation, whose kinetics are therefore evidently temperature-dependent. It is also worthy of note that the time constant of tail current decay is gradually lengthened to $\sim 80 \mathrm{~ms}$ with a stronger and/or longer preceding pulse, presumably signaling the change from true deactivating tail to resurgent tail currents (Fig. 2). The lengthening of the time constant in percentage, however, is quantitatively smaller than that in Fig. 1. This is consistent with the idea that hERG channels still undergo inactivation at $37^{\circ} \mathrm{C}$, but the tendency of inactivation seems to be decreased. In other words, the steady-state distribution between the open and inactivated states in Scheme 1 is much more in favor of the
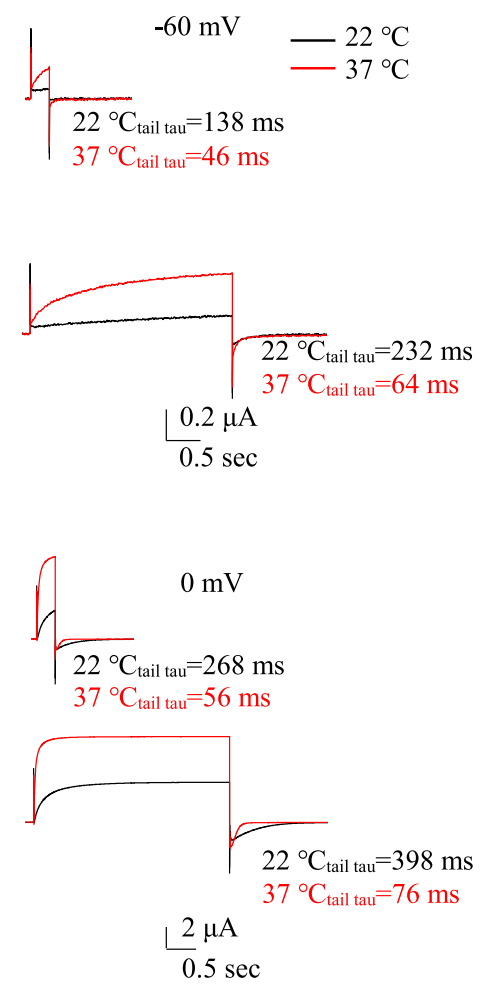
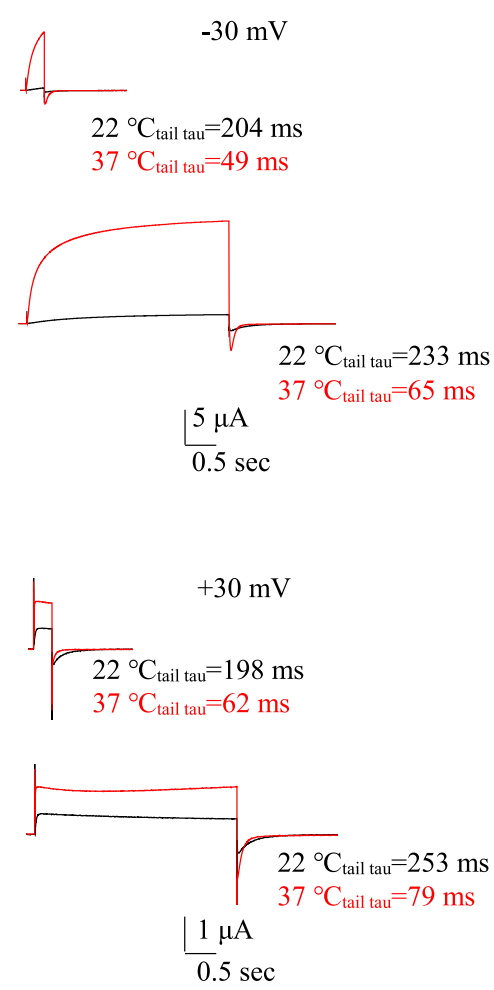

Fig. 2. Temperature dependence of gating kinetics of hERG channels. hERG currents are elicited by the same pulse protocols as that in Fig. 1. Note the much faster activation kinetics and tail current decay (time constants of the decay phases are indicated beside the traces) as well as the much larger current amplitude at $37^{\circ} \mathrm{C}$ than $22^{\circ} \mathrm{C}$. Also note the general lengthening of the time constants of tail current decay with stronger and longer preceding pulses and the possibility of decrease followed by increase of currents during a long and strong pulse (e.g., $+30 \mathrm{mV} \times 3.3$ seconds) (data of the same test pulse voltage were acquired from the same cell). 
open state at $37^{\circ} \mathrm{C}$ than at $22^{\circ} \mathrm{C}$ (see the more complicated and complete gating scheme below), and thus the tail currents may contain a larger true deactivation component of tail currents at $37^{\circ} \mathrm{C}$. It is also of note that during a long and strong pulse (e.g., $+30 \mathrm{mV} \times 3.3$ seconds), there could be a decrease and then an increase of currents, signaling the possible existence
A
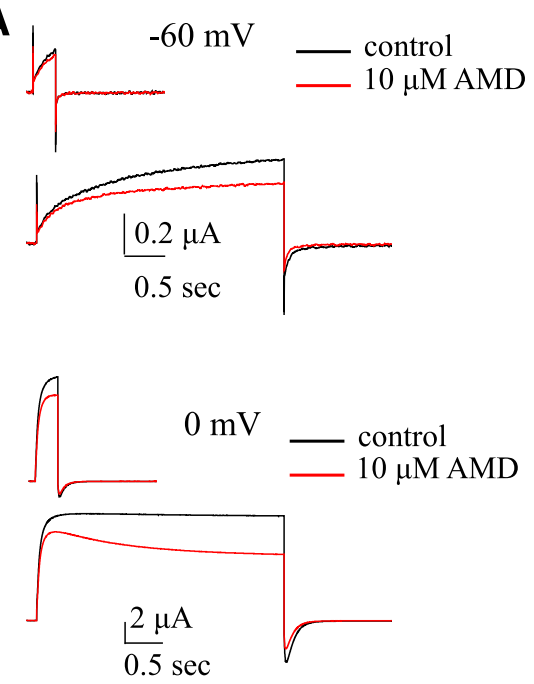

B

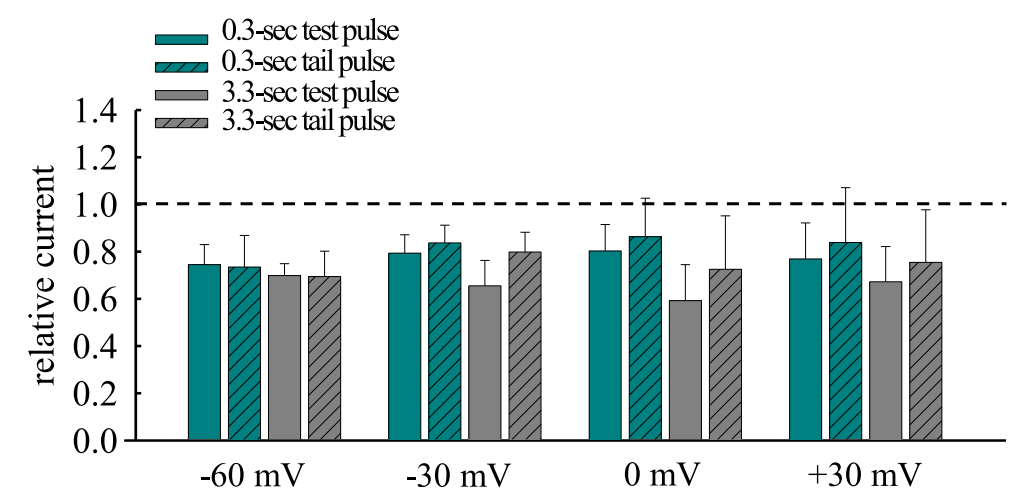

C

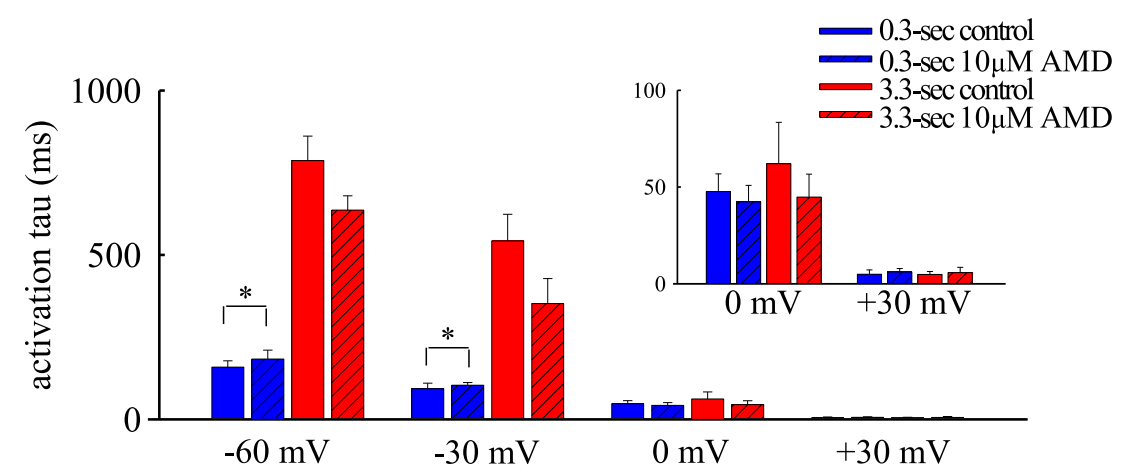

D

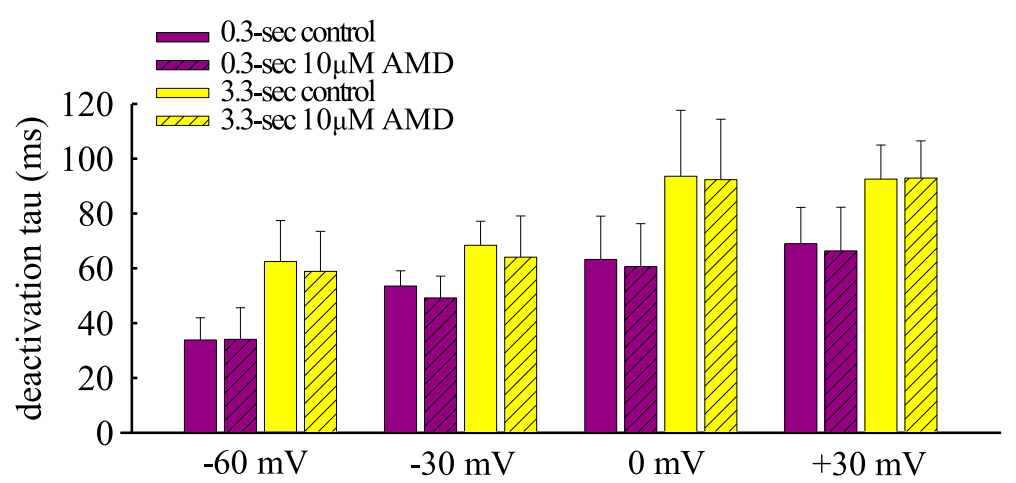

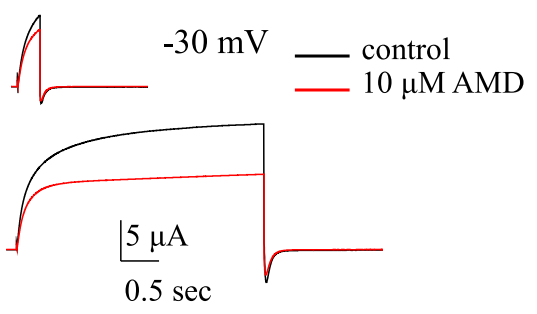
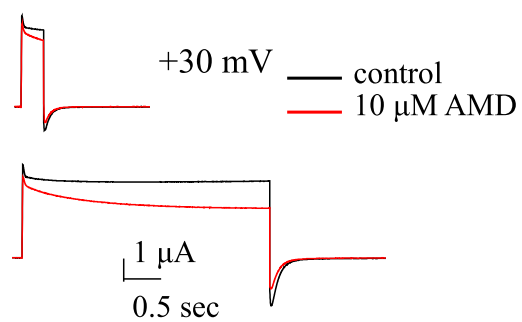

Fig. 3. AMD inhibits hERG currents by enhancement of inactivation at $37^{\circ} \mathrm{C}$. (A) hERG currents were elicited by short ( 0.3 -second) and long (3.3second) test pulses at $-60,-30,0,+30 \mathrm{mV}$ from a holding potential at $-90 \mathrm{mV}$. (B) The late sustained currents (the average currents in the last $5 \mathrm{~ms}$ of the test pulse) and the peak of tail currents in $10 \mu \mathrm{M}$ AMD are normalized to that in control to give the relative currents in the test and tail pulses $(0.3$ second, green bar; 3.3 seconds, gray bar; $n=10,10,11,10$ for $-60,-30,-0,+30$ $\mathrm{mV}$, respectively). Note the larger current reduction by $10 \mu \mathrm{M}$ AMD at 0.3 -second 0 and $+30 \mathrm{mV}$ and the weaker inhibitory effect at $0.3-$ second -60 and $-30 \mathrm{mV}$ than in Fig. 1B (paired two-tailed $t$ test, $P<0.05$ ). (C) The time constants from the monoexponential fits to the growing phase of the currents (5\% to $95 \%$ of currents) in (A) show that $10 \mu \mathrm{M}$ AMD slows channel activation from holding potential of $(-90 \mathrm{mV})$ at mild pulses (e.g., $-60 \mathrm{mV}$ ), but not strong pulses (e.g., $+30 \mathrm{mV}$ ), although the slowing effect is less prominent than that at $22^{\circ} \mathrm{C}$ in Fig. 1 . Also note this is just an approximate estimate of activation kinetics because of the contamination by inactivation (paired two-tailed $t$ test, $* P<0.05$ ). Inset figure: a magnified view of the data at 0 and +30 $\mathrm{mV}$. (D) The time constants from the monoexponential fit to the decay phase of the tail currents (from 5\% to $95 \%$ of the currents) in (A) show that despite the faster decay kinetics at $37^{\circ} \mathrm{C}, 10 \mu \mathrm{M}$ AMD has no apparent effect on the deactivation kinetics of hERG currents. Also, more depolarized and prolonged preceding test pulses by themselves still tend to lead to slower decay (longer time constant or $\tau$ of the decay phase) of the tail currents. The different pulse durations are indicated by the purple (0.3-second) and yellow (3.3second) bar, respectively ( $n=10,10,11,10$ for $-60,-30,-0,+30 \mathrm{mV}$, respectively); data of the same test pulse voltage were acquired from the same cell). 
of two different open states with distinct steady-state distribution ratios to their corresponding inactivated states (see below).

AMD Less Effectively Slows hERG Channel Activation but More Effectively Enhances Inactivation at $\mathbf{3 7}^{\circ} \mathbf{C}$. Figure 3, A-C, shows that the accelerated hERG channel activation at $37^{\circ} \mathrm{C}$ is slowed by AMD (most evident in a pulse of -60 to $-30 \mathrm{mV}$, although to a smaller extent than that at $22^{\circ} \mathrm{C}$ in Fig. 1). Meanwhile, channel inactivation is accentuated by AMD at $37^{\circ} \mathrm{C}$ (most evident in a pulse of 0 or $+30 \mathrm{mV}$; also see Supplemental Fig. 3). Interestingly, the inhibitory effect on the late sustained current in the test pulse is less and more pronounced in a pulse of -60 to $-30 \mathrm{mV}$ and 0 to $+30 \mathrm{mV}$, respectively. Although the decay of the tail currents is much faster at $37^{\circ} \mathrm{C}$ (and the time constants are gradually lengthened and saturated at $\sim 80 \mathrm{~ms}$ ), the kinetics of decay again are not changed by AMD (Fig. 3C). Also, AMD still inhibits the tail currents to a similar extent to that of the preceding sustained currents. It seems that AMD has a qualitatively similar action on hERG channels at both $22^{\circ} \mathrm{C}$ and $37^{\circ} \mathrm{C}$. But the quantitative differences, especially those relevant to the pathophysiological and clinical settings, may be worth further exploring.

AMD Binds to the Deactivated hERG Channel with an Apparent Dissociation Constant of $\sim 1.4 \mu \mathrm{M}$. We have seen in Supplemental Fig. 2 that 1 to $100 \mu \mathrm{M}$ AMD concentrations dependently inhibits the currents in a prolonged pulse of -60 to $-30 \mathrm{mV} \times 120$ seconds, reasonably approximating a steady-state condition. The $\mathrm{IC}_{50}$ is most likely 1 to $3 \mu \mathrm{M}$ at $-60 \mathrm{mV}$, and probably is higher toward more positive potentials. This is, however, not an ideal estimate of dissociation constant because of the mixture of different gating states of the channel in the long pulse. In view of the apparent effect of AMD on the activation kinetics of the hERG channel, we endeavored to investigate the possibility of AMD binding to the relatively fully deactivated state and thus a more pure gating state of the channel. Figure 4, A and B, and
A

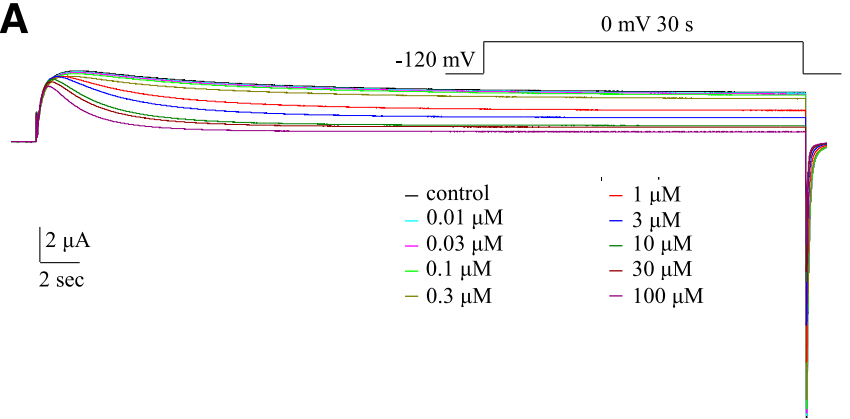

B

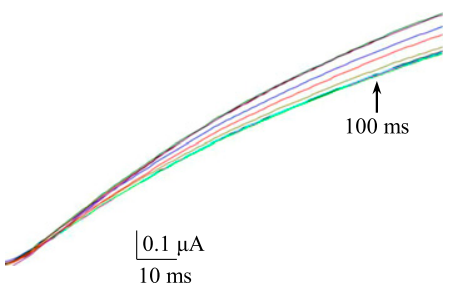

$\mathbf{C}$
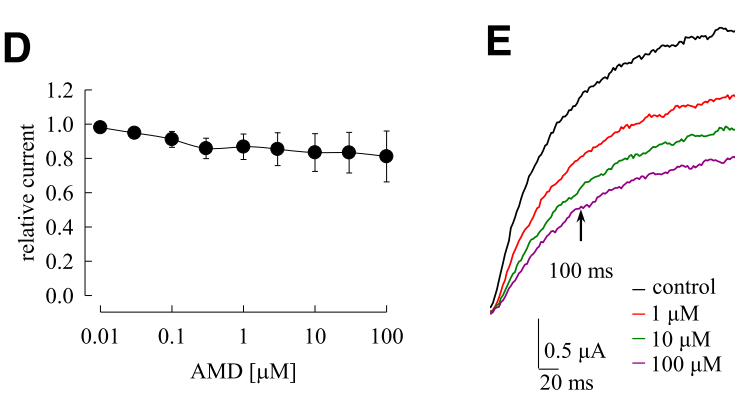

$\mathbf{F}$

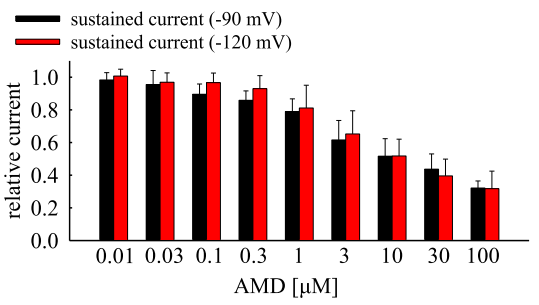

$\operatorname{AMD}[\mu \mathrm{M}]$
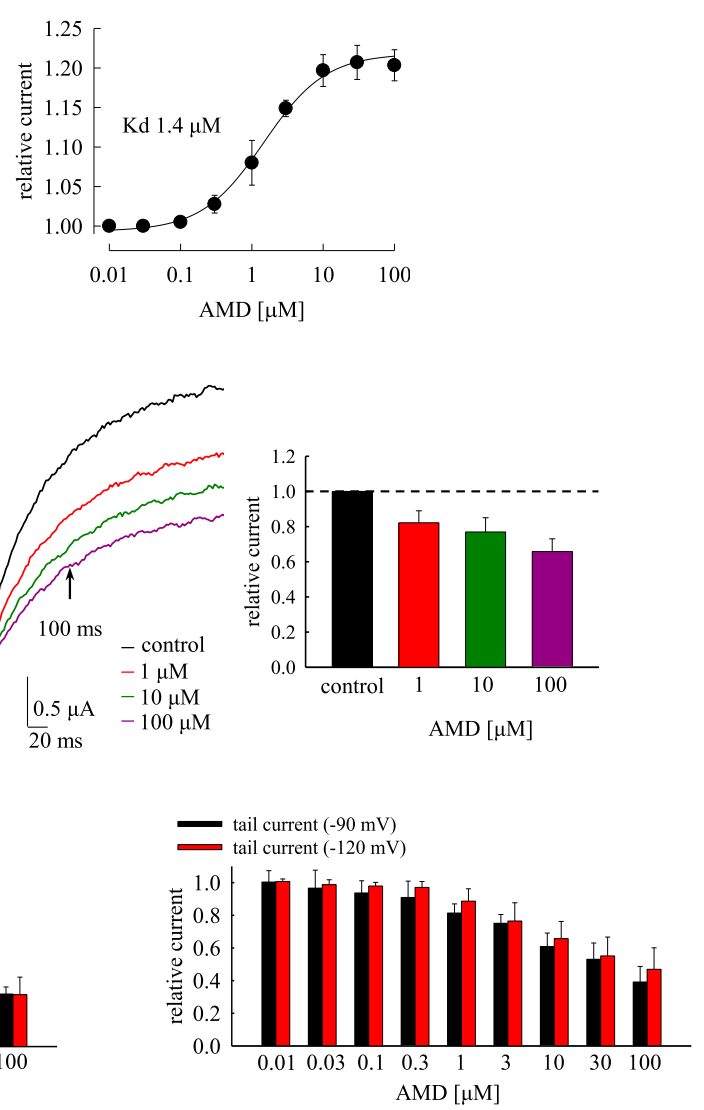

Fig. 4. Concentration-dependent enhancement effect of AMD on the initial activation rate of hERG channels. (A) hERG currents in different concentrations of AMD at $22^{\circ} \mathrm{C}$ are depicted by different colors. The holding potential is $-120 \mathrm{mV}$, and the test pulse is $0 \mathrm{mV}$ $\times 30$ seconds. The intersweep interval is 1.5 to 3.5 minutes, which is enough to fully recover all inactivated channels back to the resting state. (B) A closer view of the initial activation phase in (A). (C) The current amplitude at $100 \mathrm{~ms}$ [arrow in (A)] of the test pulse in different concentrations of AMD is normalized to that in control to give the relative current, which is then plotted against AMD concentration and fitted with a Hill equation to give an apparent $K_{\mathrm{d}}$ value of $1.4 \mu \mathrm{M}(n=7)$. (D) With the same test pulse voltage and duration in (A), but a different holding potential at -90 $\mathrm{mV}$, there is no manifest enhancement effect of AMD on the initial phase of channel activation measured in the same way as that in (C) $(n=5)$. (E) With the same pulse protocol in (A) but at $37^{\circ} \mathrm{C}$, the current amplitude at $100 \mathrm{~ms}$ (arrow, left panel) is normalized with same procedure in (C) and (D) to give the relative current (right panel). In contrast to the case at $22^{\circ} \mathrm{C}$ in (B), the initial activation phase is inhibited by AMD at $37^{\circ} \mathrm{C}(n=4)$. (F) The late sustained currents (the average currents in the last $5 \mathrm{~ms}$ ) in the 30 -second test pulse (left panel) and the peak of following tail currents (right panel) in AMD with different holding potential $(-90 \mathrm{mV}$ vs. $-120 \mathrm{mV})$ are normalized to that in control and plotted against the AMD concentration (red bars: holding potential at $-90 \mathrm{mV}, n=5$, and black bars: holding potential at $-120 \mathrm{mV}, n=7$ ). 
A
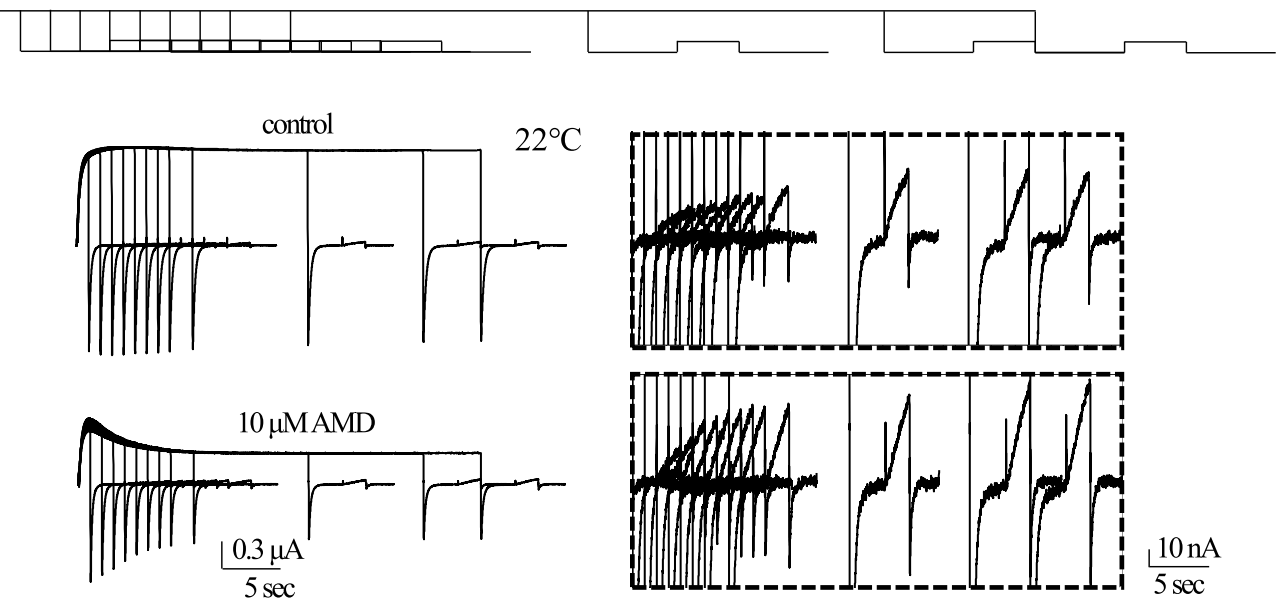

B
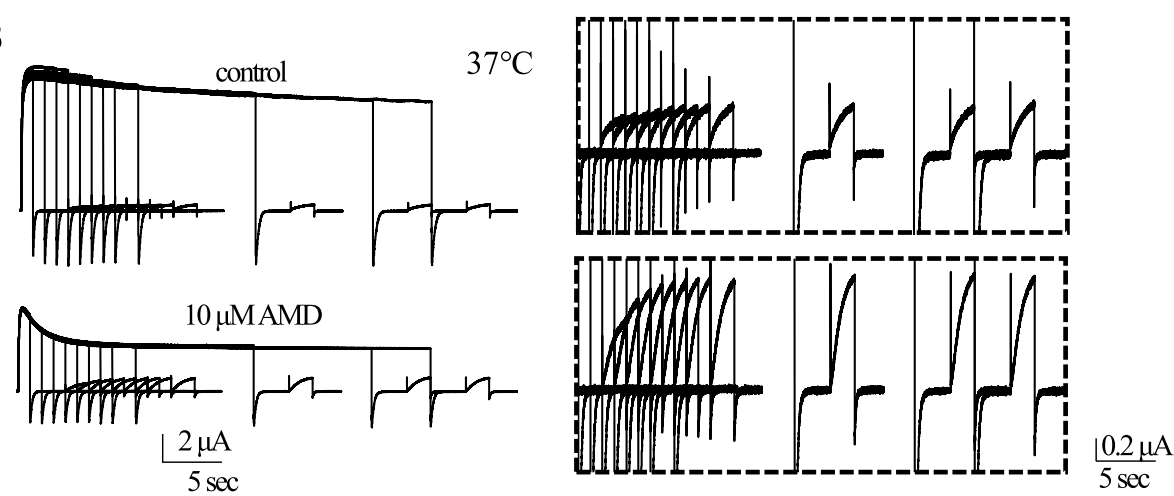

C
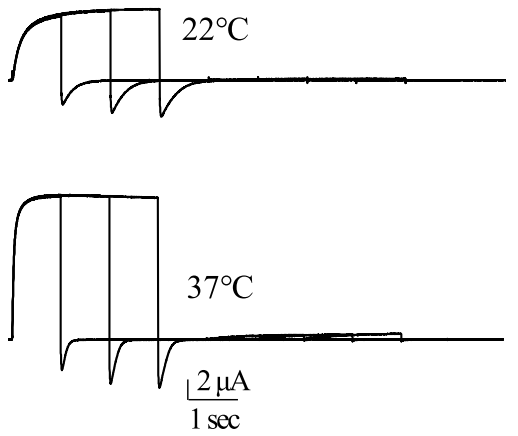

D

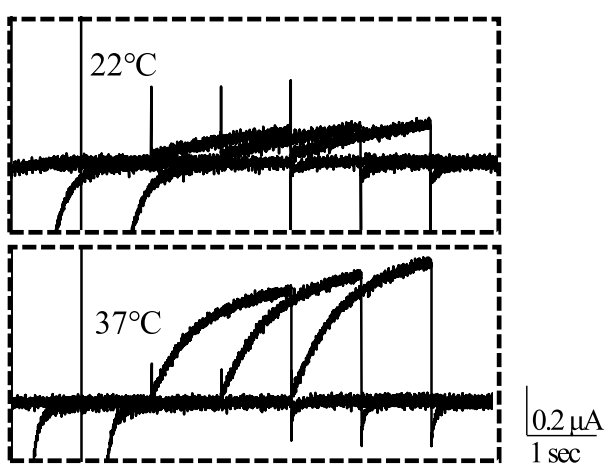

- $22^{\circ} \mathrm{C}(10 \mu \mathrm{MAMD})$

- $22^{\circ} \mathrm{C}$ (control)

- $37^{\circ} \mathrm{C}(10 \mu \mathrm{MAMD})$

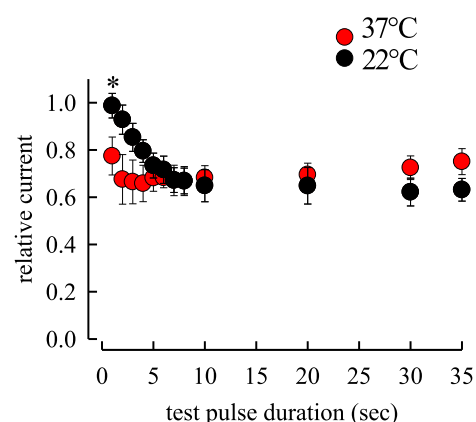

$\triangle 37^{\circ} \mathrm{C}$ (control)

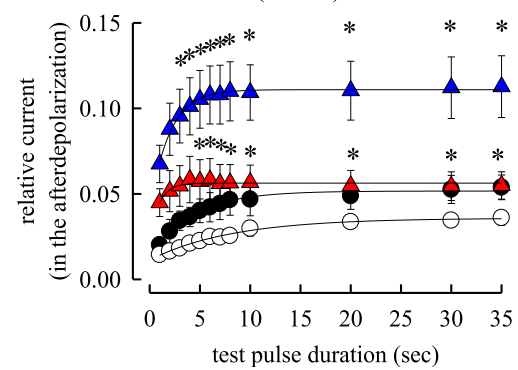

Fig. 5. Inhibition of hERG tail currents and enhancement of the currents in a mild depolarization pulse following a prepulse are dependent on temperature and prepulse duration. (A) Macroscopic current traces were acquired at $22^{\circ} \mathrm{C}$ with a protocol that a prepulse of $0 \mathrm{mV}$ was lengthened from 1 to 8 seconds $(\Delta t=1$ second $)$ and then to $10,20,30$, and 35 seconds from a holding potential of $-90 \mathrm{mV}$. After a gap potential at $-90 \mathrm{mV} \times 3$ seconds, a mild depolarization test pulse at $-60 \mathrm{mV} \times 2$ seconds (the afterdepolarization) was given before returning back to $-90 \mathrm{mV}$. The intersweep interval is 1.5 to 3.5 minutes, which is enough to fully recover all inactivated channels back to the resting state. The sweeps in control and in $10 \mu \mathrm{M}$ AMD are shown in the 
Supplemental Fig. 4 document the change of activation kinetics, especially the initial kinetics of the hERG by different concentrations of AMD from a holding potential of -120 to $0 \mathrm{mV}$, which coincides with a narrow window for a protocol to observe acceleration of the initial activation by AMD. Fitting with a one-to-one binding curve to the initial activation kinetics reaction reveals an apparent $K_{\mathrm{d}}$ of $\sim 1.4 \mu \mathrm{M}$ (Fig. $4 \mathrm{C}$ ), which could be reasonably ascribed to binding of AMD to the presumably fully deactivated or resting hERG channels (at $-120 \mathrm{mV}$ ) because the measurement is focused on the initial part of activation. In contrast, the enhancement effect of AMD becomes much less evident when the holding potential is set at $-90 \mathrm{mV}$ (Fig. 4D), probably because of the distribution of the channel in less fully deactivated states at the more positive holding potentials and thus more contamination of the activation from the intermediate deactivated states by inactivation. We also repeated the same experiments with a holding potential of $-120 \mathrm{mV}$ at $37^{\circ} \mathrm{C}$. No enhancement but inhibition or slowing of the initial activation phase was demonstrated (Fig. 4E), presumably because the initial activation from the most deactivated state (at $-120 \mathrm{mV}$ ) is already quite fast at $37^{\circ} \mathrm{C}$. In other words, the apparent enhancement only at $22^{\circ} \mathrm{C}$ but not $37^{\circ} \mathrm{C}$ is that the initial activation from $-120 \mathrm{mV}$ (presumably from $\mathrm{C}_{1}$ or the most deactivated state) is already quite fast at $37^{\circ} \mathrm{C}$. This is also the reason that there is no apparent enhancement effect even at $22^{\circ} \mathrm{C}$ if the initial activation is from $-90 \mathrm{mV}$ (where channel activation is presumably mostly from $\mathrm{C}_{2}$ or $\mathrm{C}_{3}$ rather than $\mathrm{C}_{1}$ and thus is already accelerated compared with that from $-120 \mathrm{mV}$ ). In spite of the difference of initial activation phase at holding potential of -90 and $-120 \mathrm{mV}$, the inhibitory effect of AMD on the late currents in the $0 \mathrm{mV}$ pulse or on the tail currents are very similar (Fig. 4F), indicating that the different findings at -90 and $-120 \mathrm{mV}$ holding potential are indeed limited to the initial current or channel activation. In any case, AMD seems to bind to the deactivated hERG channel with a binding constant in the low micromolar range, which is well in accordance with the therapeutic concentrations of AMD.

AMD Inhibits Tail hERG Currents by Facilitation of a Silent Route of Recovery from Inactivation. It is well known that hERG channels could recover from inactivation via an open state (e.g., Scheme 1), giving rise to a prominent resurgent tail current. In Figs. 1 and 2, we have seen the evidently smaller resurgent tail currents at $37^{\circ} \mathrm{C}$ than at $22^{\circ} \mathrm{C}$ (especially if taking the corresponding sustained currents into consideration). Moreover, the tail resurgent currents are unequivocally inhibited by AMD. The kinetics of tail current decay, however, are not proportionally altered in the presence of AMD. This is very difficult to envisage if AMD only affects hERG channel activation and inactivation. For an explanation of these phenomena, Scheme 1 is inadequate and Scheme 2 is proposed.

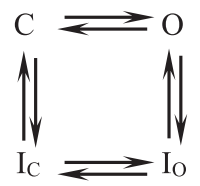

Scheme 2

Scheme 2 indicates at least two possible routes of recovery from inactivation. $I_{O}$ is the predominant inactivated state during a step depolarization. $\mathrm{I}_{\mathrm{O}}$ could recover to state $\mathrm{C}$ during the hyperpolarization phase following the step depolarization either via state $\mathrm{O}$ (to generate tail or resurgent currents and thus designated as the resurgent route) or via state $I_{C}$, which has the activation gate closed before opening of the deinactivation gate and thus would not allow current flow in the recovery processes (the silent route). The inhibition of the resurgent tail currents by AMD therefore is most likely ascribable to facilitation of the silent route of recovery from inactivation, so that the kinetics of tail current decay are unchanged. We therefore explored the recovery from inactivation process in detail. At $22^{\circ} \mathrm{C}$, it is evident that the inhibition of tail currents by AMD is more manifest with lengthening of the test pulse (Fig. 5, A and D). Most interestingly, the currents elicited by the following mild pulse at $-60 \mathrm{mV}$ (the afterdepolarization) are much larger at $37^{\circ} \mathrm{C}$ than at $22^{\circ} \mathrm{C}$ (Fig. 5, B and C), and are further enhanced by AMD (the enhancement effect of AMD is manifest at $22^{\circ} \mathrm{C}$, but even more marked at $37^{\circ} \mathrm{C}$; Fig. 5D). These features are consistent with the faster channel activation from the intermediate deactivated states at higher temperatures, and thus would make AMD an even better antiarrhythmic at $37^{\circ} \mathrm{C}$ than at $22^{\circ} \mathrm{C}$ (see Discussion).

There Are Two Distinct Open and Correlative Inactivated States with Different Propensity for the Silent Route of Recovery. We have seen that AMD facilitates entry into inactivated states as well as silent recovery from inactivation to inhibit hERG currents in different phases. We have also noted that the tail currents either remain at about the same size (Fig. $5 \mathrm{~B} ; 37^{\circ} \mathrm{C}$ ) or could be gradually decreased with the lengthening of the prepulse (e.g., Fig. 5A; Supplemental Fig. 5). This is very hard to envisage if there is just one open state (and one directly associated inactivated state) in the gating scheme of hERG channels, in which case the increased inactivation with stronger or longer depolarizing test pulses must be associated with an increase of the resurgent or tail current in the following gap. We therefore propose that there must be at least two distinct open states

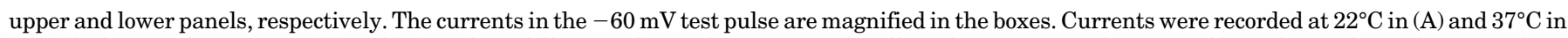

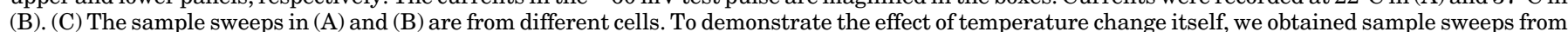

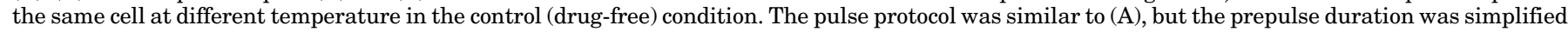

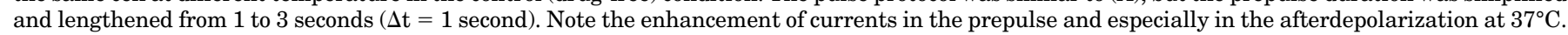

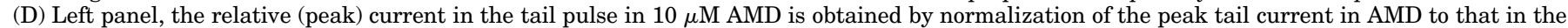

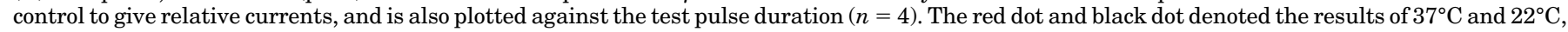

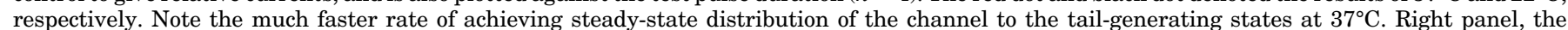

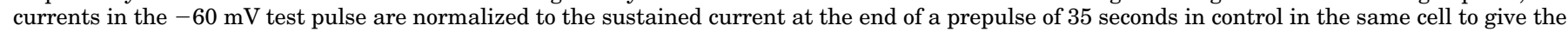

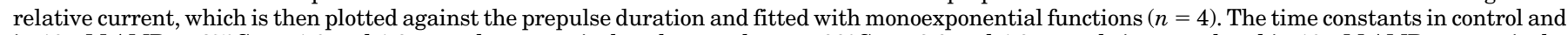

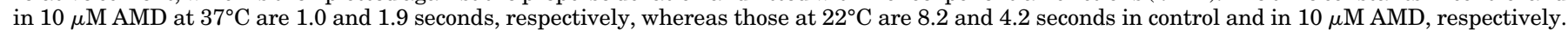
Note the much larger effect of $\mathrm{AMD}$ at $37^{\circ} \mathrm{C}$ than at $22^{\circ} \mathrm{C}$ (nonpaired one-tailed $t$ test, ${ }^{*} P<0.05$ ). 
A
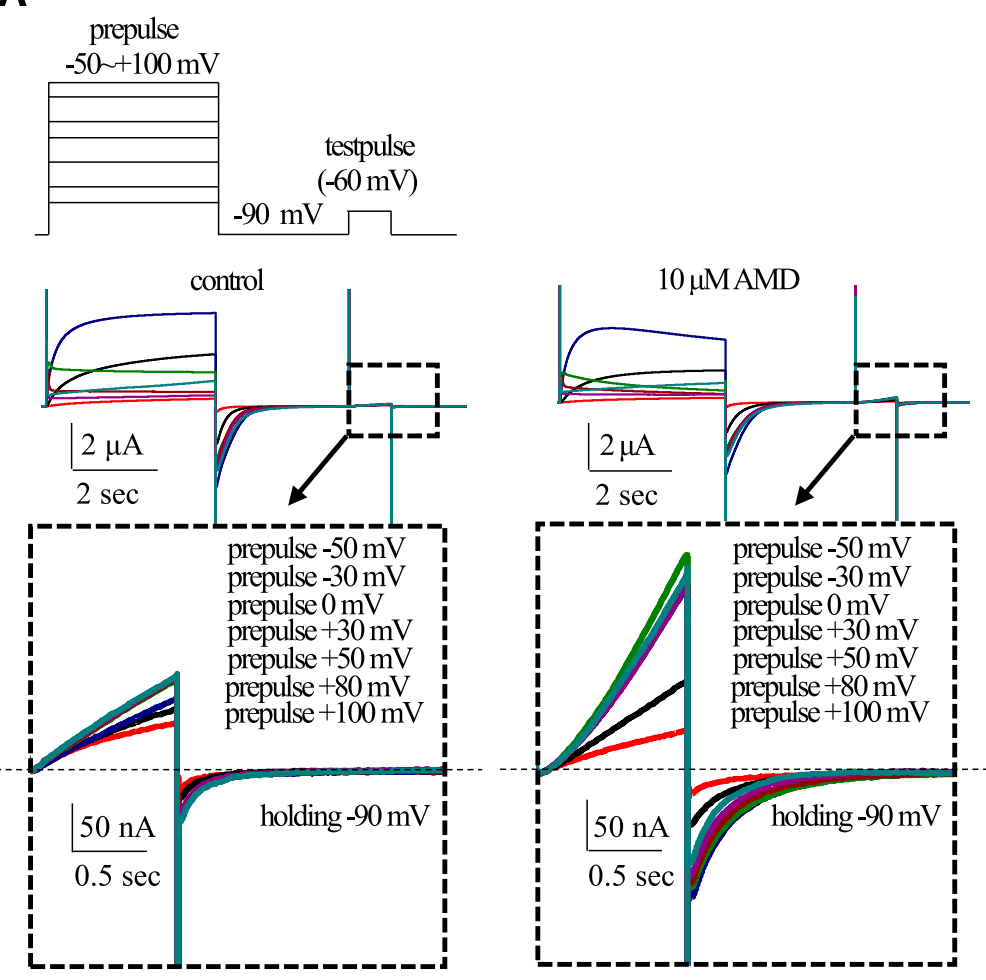

D
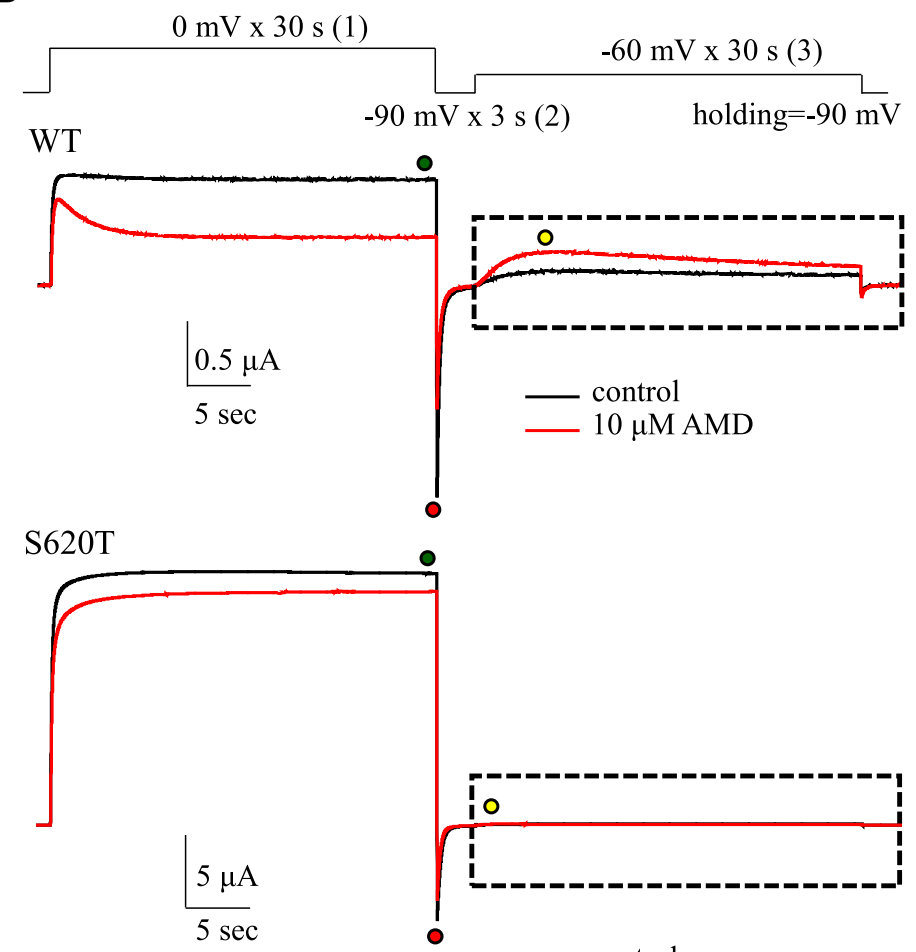

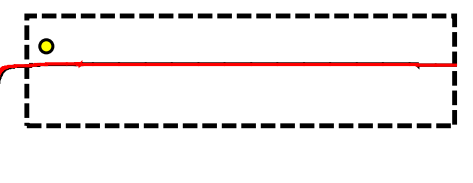

control

$10 \mu \mathrm{M}$ AMD
B

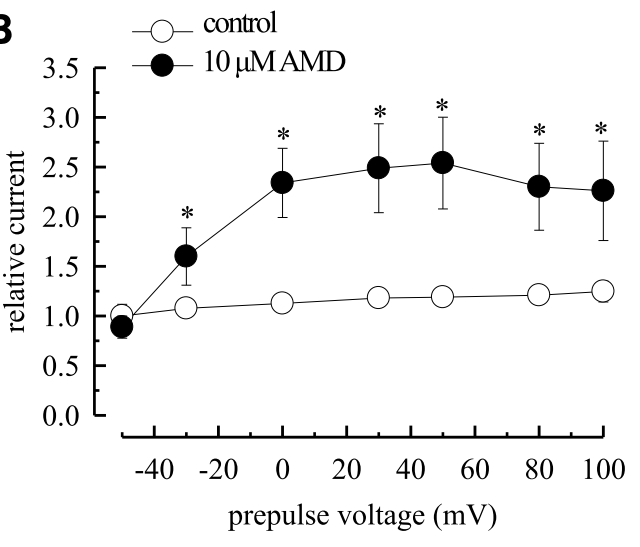

C

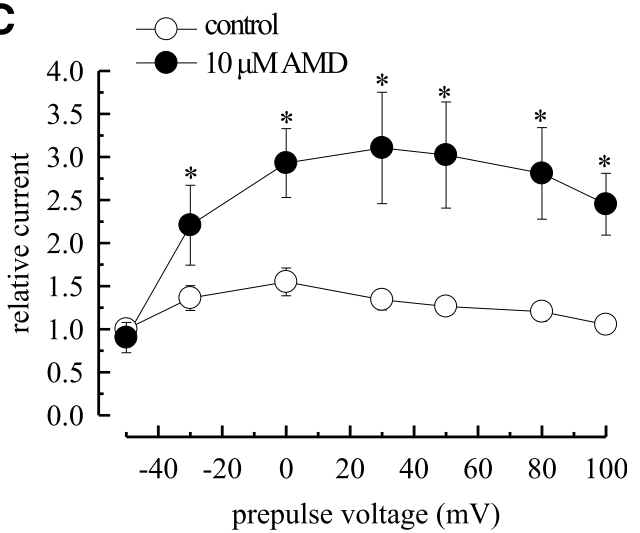

E

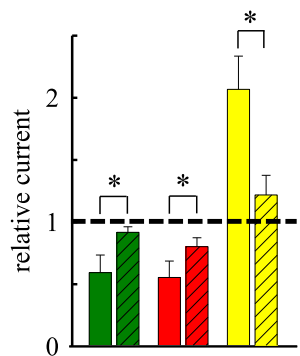

Fig. 6. Voltage dependence of the enhancement effect of AMD on hERG currents in the preceding pulse (prepulse). (A) The prepulses were set to -50 to $+100 \mathrm{mV} \times 4$ seconds from a holding potential of $-90 \mathrm{mV}$. The prepulse was followed by a gap $(-90 \mathrm{mV} \times 3 \mathrm{~seconds})$ and then a test pulse $(-60 \mathrm{mV} \times 1$ second). Boxes: the hERG currents elicited by the test pulse in control (left) and in $10 \mu \mathrm{M}$ AMD (right) are magnified. (B and C) The currents elicited by the $-60 \mathrm{mV}$ test pulse (part B) and the following tail current at $-90 \mathrm{mV}$ (part C) are normalized to those after a prepulse at $-50 \mathrm{mV}$ in control in the same cell to give the relative current, which is then plotted against the prepulse voltage $(n=26,26,37,28,30,26$, and 19 for $-50,-30,0,+30,+50,+80$, and $+100 \mathrm{mV}$, 
$\left(\mathrm{O}_{1}\right.$ and $\mathrm{O}_{2}$; see Scheme 3 below), each with directly associated inactivated states $\left(\mathrm{I}_{\mathrm{O} 1}\right.$ and $\left.\mathrm{I}_{\mathrm{O} 2}\right)$, which have differential propensity of the route of recovery route (Scheme 3 , where $\mathrm{I}_{\mathrm{O} 1}$ is more prone to take the silent route of recovery than $\mathrm{I}_{\mathrm{O} 2}$, but it takes time to reach a steady-state distribution to $\mathrm{I}_{\mathrm{O} 1}$ via $\mathrm{O}_{1}$, $\mathrm{O}_{2}$, and $\mathrm{I}_{\mathrm{O} 2}$ ).

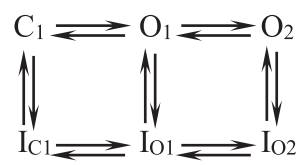

Scheme 3

The transitions between $\mathrm{O} 1$ and $\mathrm{O} 2$ are further investigated with a strong prepulse at +30 to $+60 \mathrm{mV}$ (Supplemental Fig. 5). It is clear that the relative size of tail currents and the gradual decrease of tail currents in AMD are in general much more similar to the case of a prepulse at $0 \mathrm{mV}$ (and $22^{\circ} \mathrm{C}$; Fig. 5A). The decrease of tail resurgent currents therefore is correlative to the distribution of channels from $\mathrm{I}_{\mathrm{O} 2}$ to $\mathrm{I}_{\mathrm{O} 1}$, which could be evidently facilitated by AMD, but not a prepulse of stronger depolarization. The voltage dependence of the transitions between the two open states therefore should be quite lower than C-O or Ic-Io transitions (see Discussion).

AMD Enhances hERG Currents at a Mild Afterdepolarization by Slowing of the Overall Kinetics of Recovery from Inactivation. In Fig. 5, A and B, we have demonstrated that the hERG currents in a mild depolarization following the gap (i.e., afterdepolarization) is enhanced by AMD. Figure 6A examines the possibility in more detail and shows that $\left(\right.$ at $22^{\circ} \mathrm{C}$ ) the enhancement effect is much more prominent with more depolarized prepulse between -40 and $+20 \mathrm{mV}$, and then reaches a plateau between +20 and $+100 \mathrm{mV}$, consistent with the idea that during the 4 -second prepulse, more inactivation channels are generated with a voltage change from -40 to $+20 \mathrm{mV}$, but most channels would have reached the inactivated state at a prepulse potential $+20 \mathrm{mV}$ or above. The very similar enhancement effect in Fig. 6, B and C, indicates that it is nearly a true tail or deactivating current following the $-60 \mathrm{mV} \times 1$-second afterdepolarization. Moreover, the inactivation-removed S620T mutation also abolishes not only the inhibitory effect of the action of AMD on the current during the step depolarization and the following tail pulse, but also the enhancement effect of AMD on the current during the afterdepolarization (Fig. 6, D and E). It is very interesting that AMD should markedly inhibit hERG currents elicited by $\mathrm{a}-60 \mathrm{mV}$ pulse if there are no preceding pulses (e.g., Figs. 1 and 3; Supplemental Fig. 3), but markedly enhances the currents if there is a preceding pulse resulting in significant channel inactivation. It is plausible that the direct cause of the enhancement effect is activation of hERG channels not from the fully but from the intermediate deactivated states because the intervening gap is not long enough to allow a full recovery process (recovery back to the fully deactivated state), and AMD further slows this recovery process. Supplemental Fig. 6 shows that the enhancement effect is in general larger in the presence of AMD, and gets smaller with lengthening of the gap. Moreover, the decay of the enhancement effect is markedly slower in AMD than in control (time constants 43.8-45.7 seconds in AMD vs. 11.6-19.8 seconds in control at a holding potential of $-90 \mathrm{mV}$; Supplemental Fig. 6), well substantiating the idea of slower recovery from inactivation (thus less propensity to stay in the fully deactivated state with a limited length of gap and consequently more activation at the subsequent afterdepolarization) in AMD. In other words, more hERG channels would be in the intermediate closed states with a relatively short recovery period after a prepulse (Scheme 4 , where $\mathrm{C}_{2}$ is the intermediate closed or deactivated state, and $\mathrm{C}_{1}$ is the fully deactivated state; $\mathrm{I}_{\mathrm{C} 2}$ and $\mathrm{I}_{\mathrm{C} 1}$ are the deactivated and also inactivated states corresponding to $\mathrm{C}_{2}$ and $\mathrm{C}_{1}$, respectively).

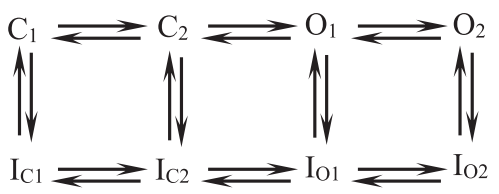

Scheme 4

hERG channels are therefore more easily activated or enhanced by an afterdepolarization, if the depolarization is not so widely separated from the previous one (i.e., if the depolarization is an afterdepolarization). This would be especially true at $37^{\circ} \mathrm{C}$, where channel activation is itself much faster than at $22^{\circ} \mathrm{C}$, and again could be a major advantage against premature afterdepolarization in the genesis of cardiac arrhythmias especially at $37^{\circ} \mathrm{C}$ (see Discussion).

AMD Shows Temperature-Dependent and Use-Dependent Modification Effect on hERG Currents in Pulse Protocols Simulating Normocardia and Tachycardia. With pulse protocols simulating normocardia and tachycardia (Fig. 7), it is clear that inhibition of hERG currents by AMD during the depolarization prepulse and the following gap (i.e., tail resurgent currents) are both use-dependent, although it is definitely faster to achieve the steady-state effect at $37^{\circ} \mathrm{C}$ than $22^{\circ} \mathrm{C}$ and at $1.67 \mathrm{~Hz}$ than $1.11 \mathrm{~Hz}$. Because the cardiac plateau potential is characterized by short ( $\sim 300 \mathrm{~ms}$ in length) and strong $(0$ to $+30 \mathrm{mV})$ depolarization, and the interpulse interval (the repolarization interval) between two plateaus is only a few hundred milliseconds in physiologic conditions, the inactivated channels may accumulate with repeated pulses to make the use dependence. The inhibition of hERG currents during the depolarization prepulses and the intervening repolarization steps (i.e., the tail currents) are more pronounced at $37^{\circ} \mathrm{C}$ than $22^{\circ} \mathrm{C}$ in most cases (see also Fig. 1B; Fig. 3B; Supplemental Fig. 3). The plateau-prolongation effect of AMD

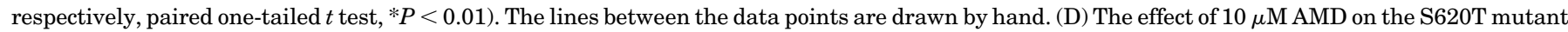

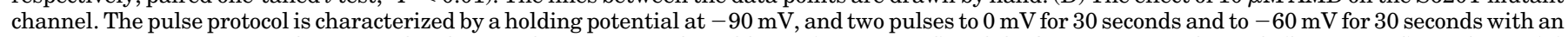

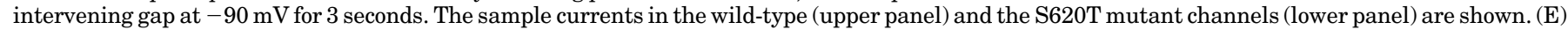

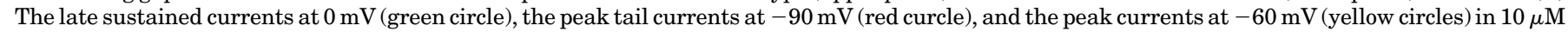

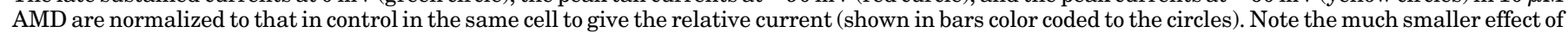
AMD in the mutant than in the wild-type channels (all $n=5$, nonpaired two-tailed $t$ test, $* P<0.01$ ). 
A $0 \mathrm{mV} \times 0.3 \mathrm{sec}$

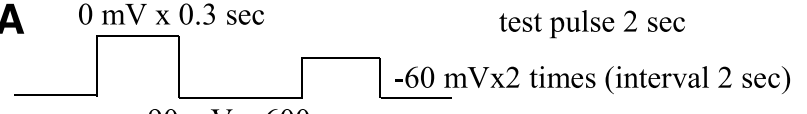
$-90 \mathrm{mV} \times 600 \mathrm{~ms}$ train repeated 16 times
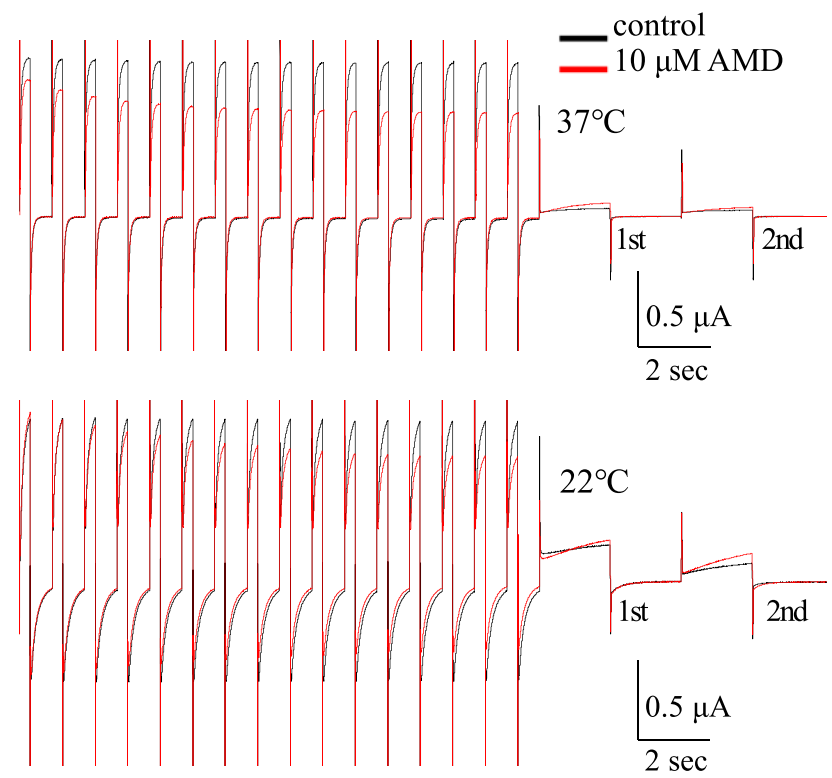

B

$1.11 \mathrm{~Hz}$

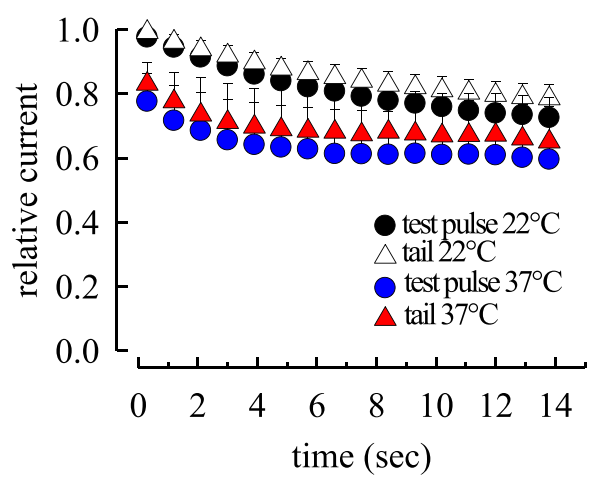

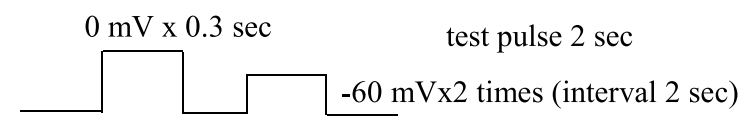

$-90 \mathrm{mV} \times 300 \mathrm{~ms}$

train repeated 24 times
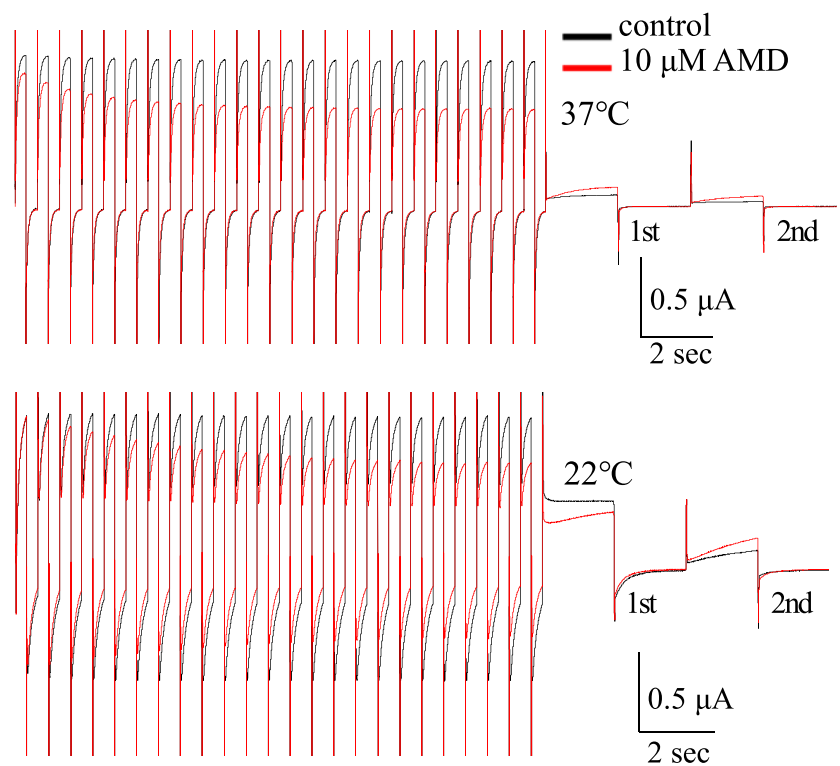

$1.67 \mathrm{~Hz}$

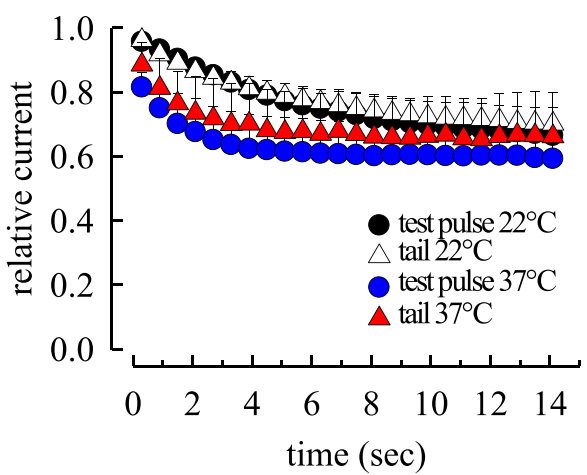

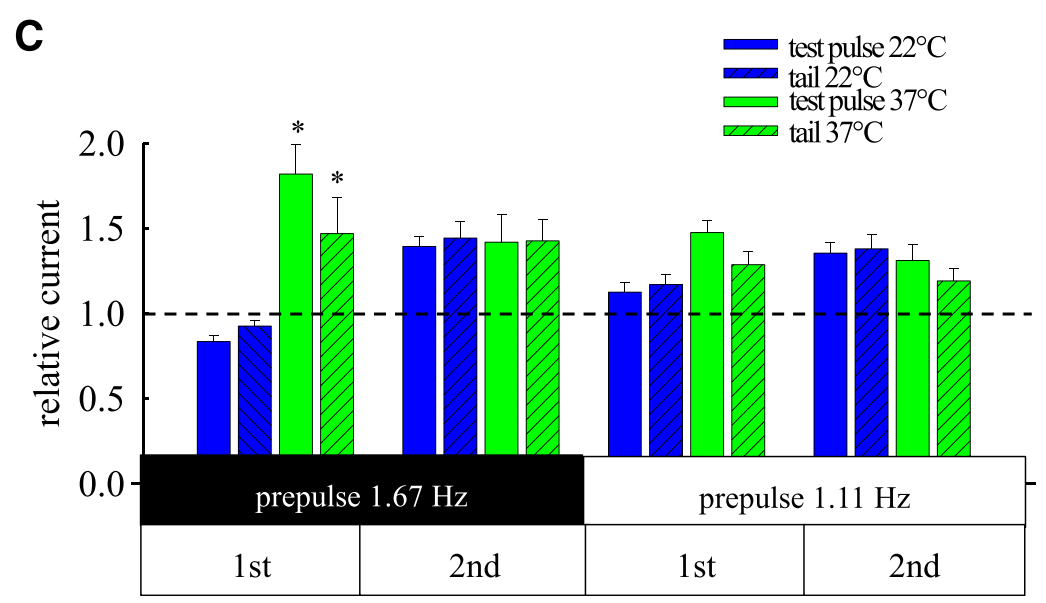

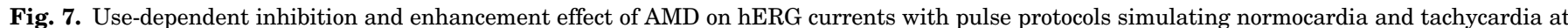

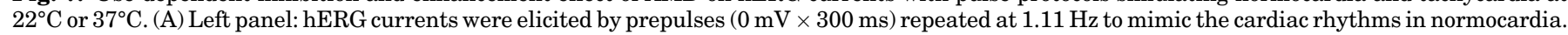

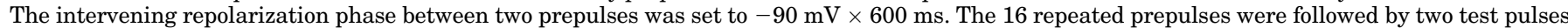

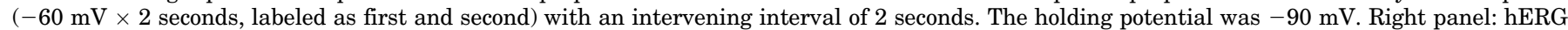

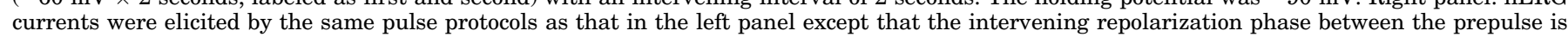

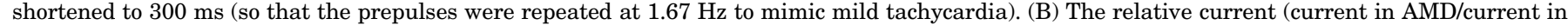


therefore is very likely dependent on the temperature and cardiac rhythms at least within a feasible range. The inhibition of tail currents by AMD would in theory slightly decrease the assurance of a rapid and relatively undisturbed repolarization phase once the plateau phase is over and membrane repolarization ensues (see Discussion). In this regard, the hERG currents elicited by afterdepolarization $-60 \mathrm{mV}$ after the foregoing repeated pulses are markedly enhanced rather than inhibited by AMD (see also Figs. 5 and 6; Supplemental Fig. 6). This effect is well more pronounced with tachycardia than normocardia, and at $37^{\circ} \mathrm{C}$ than $22^{\circ} \mathrm{C}$. Many more hERG currents are thus available to counteract the afterdepolarization or premature beat in the presence of AMD especially for a condition of tachycardia or tachyarrhythmia at $37^{\circ} \mathrm{C}$ (i.e., more use-dependent enhancement of hERG currents of AMD during an early or delayed afterdepolarization following a repolarization phase; see Discussion).

\section{Discussion}

The Characteristics of hERG Channel Gating: The Versatile Routes of Development of and Recovery from Inactivation in Terms of Trespassing the Open States. hERG channels are well known for their faster inactivation than activation kinetics (at relative strong depolarization pulses) and the occurrence of resurgent tail currents upon repolarization (i.e., recovery from inactivation via the resurgent route) (Vandenberg et al., 2004). The former could be readily envisaged with the relatively enhanced $\mathrm{C} \rightarrow \mathrm{I}$ transitions than $\mathrm{C} \rightarrow \mathrm{O}$ transitions in Fig. 8. The molecular routes of recovery from inactivation have not been fully characterized, although it has been inferred that hERG channels may be inactivated or recover from inactivation without trespassing the open state (Luo and Rudy, 1994; Clancy and Rudy, 2001; Lu et al., 2001). We demonstrate that, in contrast to the resurgent route of recovery where the inactivation gate reopens before the closure of the activation gate and an open state is therefore trespassed, there is a silent route of recovery where the inactivation gate reopens after the closure of the activation gate (Cuello et al., 2010; Perry et al., 2013) (see the gating scheme in Fig. 8; the $\mathrm{I}_{\mathrm{O} 2}$ to $\mathrm{I}_{\mathrm{O} 1}$ to $\mathrm{I}_{5}$ transitions embody the silent route, and the $\mathrm{I}_{\mathrm{O} 2}$ to $\mathrm{O}_{2}$, or $\mathrm{I}_{\mathrm{O} 1}$ to $\mathrm{O}_{1}$, and then to $\mathrm{C}_{5}$ transitions embody the resurgent route). The existence of the silent route of recovery necessarily argues for direct connections between the closed and inactivated states, or channel inactivation without trespassing the open state, which is consistent with the aforementioned explanation for the faster inactivation than activation at strong depolarization, and could also play an imperative role in the understanding of the action of AMD. In other words, this could be part of the reason that hERG currents are so much decreased without so much apparent increase in the macroscopic inactivation kinetics at strong depolarization because many channels are directly distributed to multiple intermediate closed and then multiple intermediate inactivated states from the closed states. Based on the simulation results in Fig. 8, we found that most inactivated hERG channels actually recover via the silent route. However, the small proportion going through the resurgent route is sufficient to give rise to sizable tail currents. The inactivation under consideration in this case presumably is the C-type inactivation (Schönherr and Heinemann, 1996; Wang et al., 1997; Torres et al., 2003; Jiang et al., 2005), which is ascribable to conformational changes in the external pore vestibule. Cations or drugs binding to this external pore region have been reported to have a prominent effect on the movement of voltage sensors in the $\mathrm{K}^{+}$or $\mathrm{Na}^{+}$ channel (Liu et al., 1996; Smith et al., 1996; Jiang et al., 1999; Yang and Kuo, 2002; Milnes et al., 2003; Mitcheson, 2003; Kuo et al., 2004; Zhang et al., 2004; Yang and Kuo, 2005; Yang et al., 2009; Catterall, 2010) and thus the voltage dependence of a molecular behavior. The conformational changes at the internal and external pore mouths (responsible for activation and C-type inactivation, respectively) may directly interact with each other via a recess-like structure in the pore (e.g., the S6 recess) (Yang et al., 2009) skipping the selectivity filter. The activation-inactivation coupling therefore could be established either via the movement of the voltage sensors indirectly or more direct local interactions involving the $\mathrm{S} 6$ recess or relevant structure. The complex gating processes, or more precisely the very versatile voltage dependence as well as molecular routes of activation/inactivation and recovery from inactivation of hERG channels, may thus involve many different (internal, external, and transmembrane) parts of the channel protein. This could be the reason that hERG channels are so vulnerable to different kinds of pharmacological and toxicological modulations.

The Molecular Actions of AMD on hERG Channels: Increased Voltage Dependence of Activation/Inactivation and Facilitated Silent Recovery from Inactivation Especially at $37^{\circ} \mathbf{C}$. We have shown that AMD binds to the deactivated channel with an apparent dissociation constant of $1.4 \mu \mathrm{M}$, well within the clinical therapeutic range of the drug. We have also shown that hERG channel activation is slowed by AMD at mild (i.e., -60 to $-30 \mathrm{mV}$ ) but not strong depolarization (i.e., 0 to $+30 \mathrm{mV}$ ), where a more prominent macroscopic inactivation may also be observed. It is plausible that in clinical settings AMD would already bind to most deactivated hERG channels to increase the voltage dependence of channel activation and/or inactivation. In other words, there is likely more charge movement between -30 and $0 \mathrm{mV}$ with AMD binding. Because of the faster activation and inactivation kinetics at $37^{\circ} \mathrm{C}$ than $22^{\circ} \mathrm{C}$, it is especially of note that the foregoing pharmacological attributes are sensitive to temperature. The inhibitory effect of AMD on the hERG currents is thus decreased during mild depolarization but increased at stronger depolarization at $37^{\circ} \mathrm{C}$ (Figs. 1 and 3; Supplemental Fig. 3), making AMD an even better antiarrhythmic for tachyarrhythmia at the body than room temperature (by lengthening the plateau potential, which usually reaches $0 \mathrm{mV}$ or above). In addition to the foregoing changes in the development of activation and inactivation, AMD also affects the recovery process from inactivation by facilitation of the silent route of recovery from inactivation. AMD therefore tends to inhibit the tail currents by shifting the distribution to the

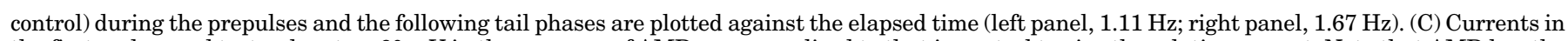

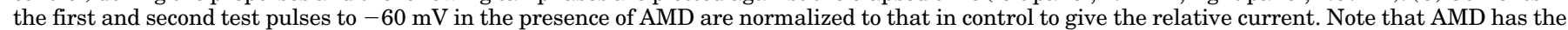
strongest enhancement effect for the first test pulse at $37^{\circ} \mathrm{C}$ (all $n=4$, nonpaired two-tailed $t$ test, ${ }^{*} P<0.01$ ). 


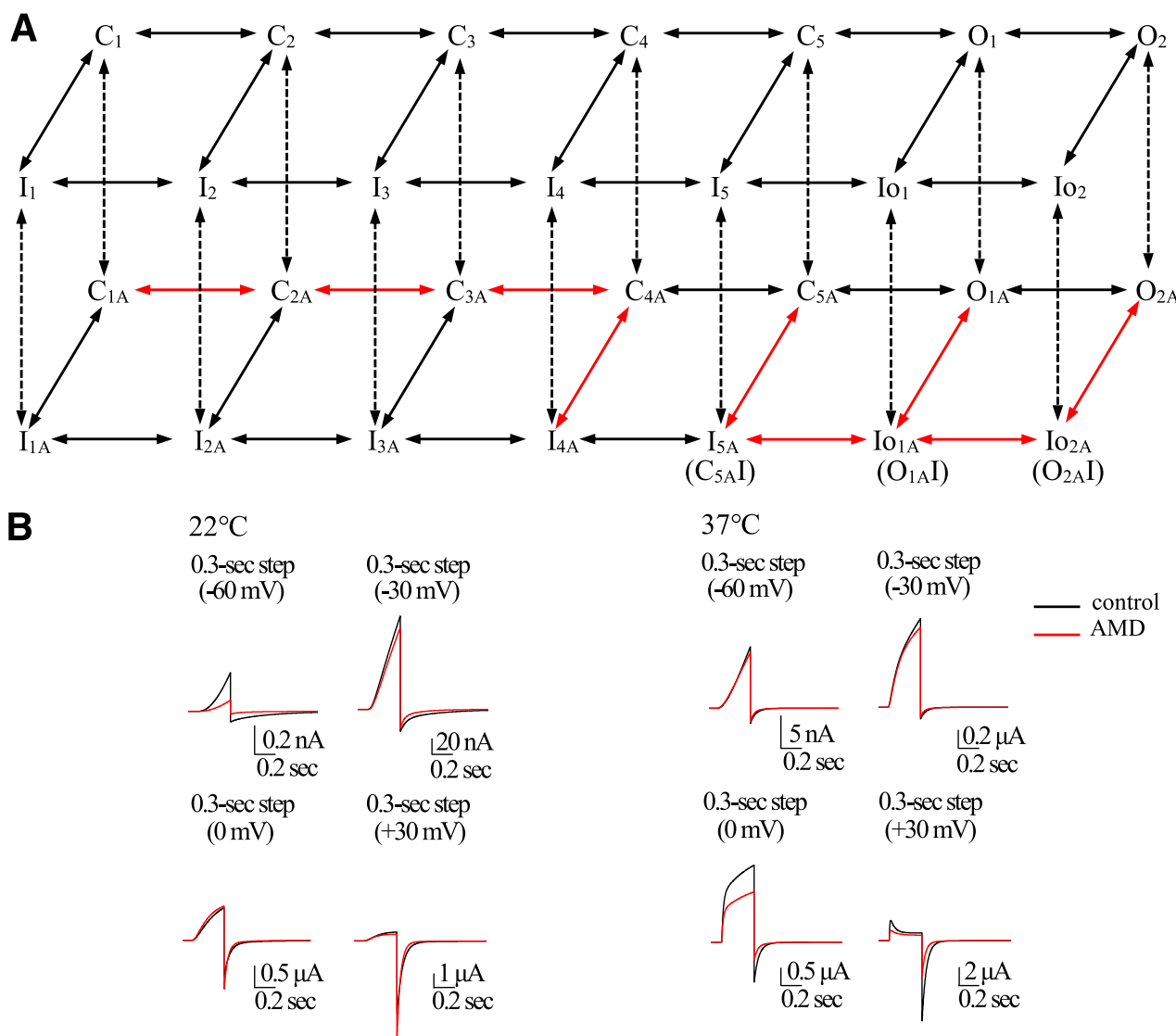

C
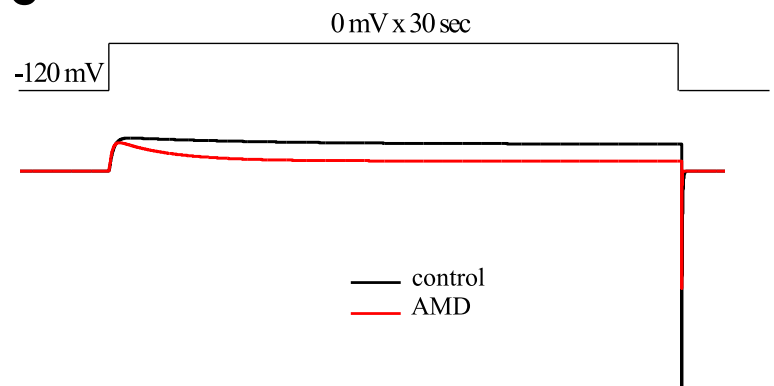

$22^{\circ} \mathrm{C}$

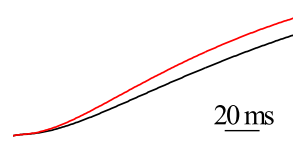

$37^{\circ} \mathrm{C}$

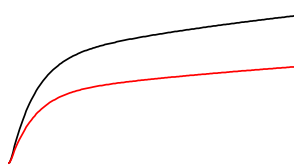

$22^{\circ} \mathrm{C}$

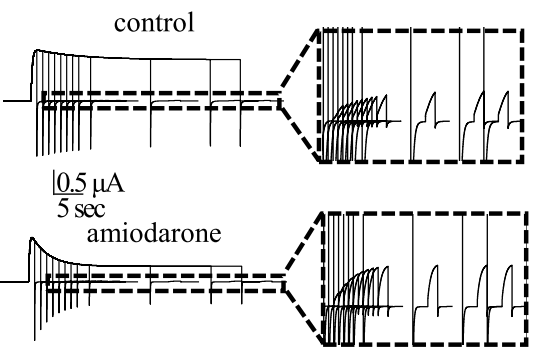

$37^{\circ} \mathrm{C}$ $\frac{10 \mathrm{nA}}{5 \sec }$ $5 \mathrm{sec}$

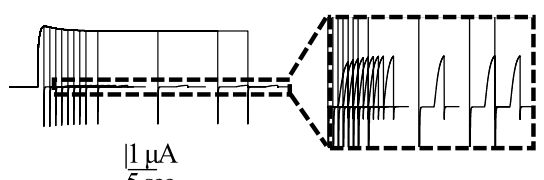

$\frac{1 \mu \mathrm{A}}{5 \mathrm{sec}}$ amiodarone

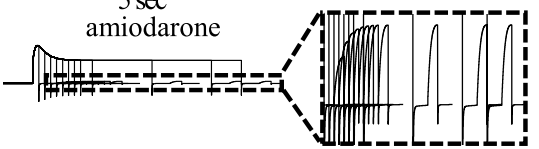

$20 \mathrm{nA}$ $5 \mathrm{sec}$

Fig. 8. A gating scheme of the hERG channel and simulation of hERG currents in control and in $A M D$ at $37^{\circ} \mathrm{C}$ than $22^{\circ} \mathrm{C}$. (A) The 14 states in the upper panel are for the control condition, and the 14 states in the lower panel are AMD-bound and stand for the gating processes in the presence of AMD. The two sets of kinetic parameters at $22^{\circ} \mathrm{C}$ are provided in Table 1 , based on which the currents at $22^{\circ} \mathrm{C}$ and $37^{\circ} \mathrm{C}$ are calculated. Note that the transitions leading into the inactivated states tend to be slower (i.e., lower $\mathrm{K}_{0}$ values) at $37^{\circ} \mathrm{C}$, demonstrating the decreased inactivation at $37^{\circ} \mathrm{C}$ than $22^{\circ} \mathrm{C}(\mathrm{Figs} .1$ and 3). Also note that the voltage dependence of the C-C transitions is in general higher in AMD than in control (Fig. 1), and that the voltage dependence of the transitions between the two open states is in general lower than the C-O transitions (Fig. 5; Scheme 3). The state-dependent binding and unbinding rates of AMD (indicated by the vertical dotted arrows) are not modeled for the sake of simplicity. This is a reasonable approximation because in therapeutic conditions the free concentrations of $\operatorname{AMD}(\sim 3 \mu \mathrm{M})$ shall be well above the dissociation constants of AMD binding to the deactivated channels (Fig. 4). There are two open states $\left(\mathrm{O}_{1}\right.$ and $\left.\mathrm{O}_{2}\right)$. At mild pulses most of hERG channels will enter the first $\mathrm{O}_{1}$ state and then the $\mathrm{I}_{\mathrm{O} 1}$ state, the recovery from which would trespass either $\mathrm{O}_{1}$ (i.e., the resurgent route for the generation of the tail currents) or $\mathrm{I}_{5}$ (the silent route). At stronger and longer depolarization, the channel would be distributed more and more to states $\mathrm{O}_{2}$ and $\mathrm{I}_{\mathrm{O} 2}$ than states $\mathrm{O}_{1}$ and $\mathrm{I}_{\mathrm{O} 1}$. The recovery from $\mathrm{I}_{\mathrm{O} 2}$ would tend to generate larger tail because of the higher rate of $\mathrm{I}_{\mathrm{O} 2} \rightarrow \mathrm{O}_{2}$ than $\mathrm{I}_{\mathrm{O} 1} \rightarrow \mathrm{O}_{1}$, and also because even if the channel takes the $\mathrm{I}_{\mathrm{O} 2} \rightarrow \mathrm{I}_{\mathrm{O} 1}$ route, it can still have another chance 
TABLE 1

Kinetic parameters for hERG channel gating in control and presented of AMD at $22^{\circ} \mathrm{C}$ and $37^{\circ} \mathrm{C}$

Voltage-dependent rates are expressed as $\mathrm{k}_{(\mathrm{v})}=\mathrm{k}_{0} \exp \left(\mathrm{k}_{1} \mathrm{~V}\right)$, where $\mathrm{k}_{(\mathrm{v})}$ stands for the transitional rate at a designated membrane potential $\mathrm{V}$ (in millivolts) at $22^{\circ} \mathrm{C}$. Transitions with negligible transitioned rates (i.e., zero) are not indicated here for the sake of simplicity. For the electronic charge displacement during activation, please also refer to the single unit of voltage sensors movement in previous hERG models (Johnson et al., 1999; Bett et al., 2011). The values are based on the root template $\left(22^{\circ} \mathrm{C}\right)$, and each transition of the conditions at $37^{\circ} \mathrm{C}$ is given. The changes in voltage dependence of activation $\left(\mathrm{C}_{1} \leftrightarrow \mathrm{C}_{2} \leftrightarrow \mathrm{C}_{3} \leftrightarrow \mathrm{C}_{4}\right)$ by $\mathrm{AMD}$ are based on the experiments in Figs. 1 and 3. The increase of silent route for entry to and recovery from inactivation by AMD ( $\left.\mathrm{I}_{\mathrm{O} 2} \rightarrow \mathrm{I}_{\mathrm{O} 1}, \mathrm{I}_{\mathrm{O} 1} \rightarrow \mathrm{I}_{5}\right)$ is based on the experiments in Fig. 5 . The slowing of transitions into inactivation $(\mathrm{C} \rightarrow \mathrm{I}$ and $\mathrm{O} \rightarrow \mathrm{I})$ at higher temperatures, and the increase of voltage dependency of inactivation $(\mathrm{C} \rightarrow \mathrm{I}$ and $\mathrm{O} \rightarrow \mathrm{I})$ when in the presence of AMD are based on the experiments in Figs. 1-3 and 5. The major changes made by AMD are shown in bold.

\begin{tabular}{|c|c|c|c|c|c|}
\hline & \multicolumn{2}{|c|}{ Control } & & \multicolumn{2}{|c|}{ Amiodarone } \\
\hline & $\mathrm{k}_{0}\left(\mathrm{~ms}^{-1}\right)$ & $\mathrm{k}_{1}\left(\mathrm{mV}^{-1}\right)$ & & $\mathrm{k}_{0}\left(\mathrm{~ms}^{-1}\right)$ & $\mathrm{k}_{1}\left(\mathrm{mV}^{-1}\right)$ \\
\hline $\mathrm{C}_{1} \mathrm{C}_{2}$ & $2.96_{\left(22^{\circ} \mathrm{C}\right)}$ vs. $5.437867_{\left(37^{\circ} \mathrm{C}\right)}$ & 0.146 & $\mathrm{C}_{1 \mathrm{~A}} \mathrm{C}_{2 \mathrm{~A}}$ & $2.96_{\left(22^{\circ} \mathrm{C}\right)}$ Vs. $5.437867_{\left(37^{\circ} \mathrm{C}\right)}$ & $0.155_{\left(22^{\circ} \mathrm{C}\right)}$ VS. $0.148_{\left(37^{\circ} \mathrm{C}\right)}$ \\
\hline $\mathrm{C}_{2} \mathrm{C}_{3}$ & $0.71821_{\left(22^{\circ} \mathrm{C}\right)}$ vs. $0.944112_{\left(37^{\circ} \mathrm{C}\right)}$ & $0.049_{\left(22^{\circ} \mathrm{C}\right)}$ vs. $0.0265_{\left(37^{\circ} \mathrm{C}\right)}$ & $\mathrm{C}_{2 \mathrm{~A}} \mathrm{C}_{3 \mathrm{~A}}$ & $0.71821_{\left(22^{\circ} \mathrm{C}\right)}$ vs. $0.944112_{\left(37^{\circ} \mathrm{C}\right)}$ & $\operatorname{0.059}_{\left(22^{\circ} \mathrm{C}\right)}$ vs. $0^{0.009} 9_{\left(37^{\circ} \mathrm{C}\right)}$ \\
\hline $\mathrm{C}_{3} \mathrm{C}_{4}$ & $0.55821_{\left(22^{\circ} \mathrm{C}\right)}$ vs. $1.698739_{\left(37^{\circ} \mathrm{C}\right)}$ & $0.002_{\left(22^{\circ} \mathrm{C}\right)}$ vs. $0.001_{\left(37^{\circ} \mathrm{C}\right)}$ & $\mathrm{C}_{3 \mathrm{~A}} \mathrm{C}_{4 \mathrm{~A}}$ & $0.55821_{\left(22^{\circ} \mathrm{C}\right)}$ vs. $1.698739_{\left(37^{\circ} \mathrm{C}\right)}$ & $0.005_{\left(22^{\circ} \mathrm{C}\right)}$ vs. $0.001_{\left(37^{\circ} \mathrm{C}\right)}$ \\
\hline $\mathrm{C}_{4} \mathrm{C}_{5}$ & $0.035321_{\left(22^{\circ} \mathrm{C}\right)}$ vs. $0.348799_{\left(37^{\circ} \mathrm{C}\right)}$ & 0.001 & $\mathrm{C}_{4 \mathrm{~A}} \mathrm{C}_{5 \mathrm{~A}}$ & $0.035321_{\left(22^{\circ} \mathrm{C}\right)}$ vs. $0.348799_{\left(37^{\circ} \mathrm{C}\right)}$ & 0.001 \\
\hline $\mathrm{C}_{5} \mathrm{O}_{1}$ & $1.05 \mathrm{E}-5_{\left(22^{\circ} \mathrm{C}\right)}$ vs. $4.7 \mathrm{E}-5_{\left(37^{\circ} \mathrm{C}\right)}$ & 0.001 & $\mathrm{C}_{5 \mathrm{~A}} \mathrm{O}_{1 \mathrm{~A}}$ & $1.05 \mathrm{E}-5_{\left(22^{\circ} \mathrm{C}\right)}$ vs. $4.96 \mathrm{E}-5_{\left(37^{\circ} \mathrm{C}\right)}$ & 0.001 \\
\hline $\mathrm{O}_{1} \mathrm{O}_{2}$ & $0.02545_{\left(22^{\circ} \mathrm{C}\right)}$ vs. $0.029361_{\left(37^{\circ} \mathrm{C}\right)}$ & 0.00071547 & $\mathrm{O}_{1 \mathrm{~A}} \mathrm{O}_{2 \mathrm{~A}}$ & 0.02863 & 0.00071547 \\
\hline $\mathrm{C}_{2} \mathrm{C}_{1}$ & $0.00001_{\left(22^{\circ} \mathrm{C}\right)}$ vs. $0.000015_{\left(37^{\circ} \mathrm{C}\right)}$ & -0.07966 & $\mathrm{C}_{2 \mathrm{~A}} \mathrm{C}_{1 \mathrm{~A}}$ & $0.00001_{\left(22^{\circ} \mathrm{C}\right)}$ vs. $0.000033_{\left(37^{\circ} \mathrm{C}\right)}$ & -0.07966 \\
\hline $\mathrm{C}_{3} \mathrm{C}_{2}$ & $0.6_{\left(22^{\circ} \mathrm{C}\right)}$ vs. $0.889337_{\left(37^{\circ} \mathrm{C}\right)}$ & -0.00166 & $\mathrm{C}_{3 \mathrm{~A}} \mathrm{C}_{2 \mathrm{~A}}$ & $0.6_{\left(22^{\circ} \mathrm{C}\right)}$ vs. $1.957876_{\left(37^{\circ} \mathrm{C}\right)}$ & -0.00166 \\
\hline $\mathrm{C}_{4} \mathrm{C}_{3}$ & $1.2_{\left(22^{\circ} \mathrm{C}\right)}$ vs. $2.204541_{\left(37^{\circ} \mathrm{C}\right)}$ & -0.00166 & $\mathrm{C}_{4 \mathrm{~A}} \mathrm{C}_{3 \mathrm{~A}}$ & $1.2_{\left(22^{\circ} \mathrm{C}\right)}$ Vs. $3.142763{ }_{\left(37^{\circ} \mathrm{C}\right)}$ & -0.00166 \\
\hline $\mathrm{C}_{5} \mathrm{C}_{4}$ & $1.8_{\left(22^{\circ} \mathrm{C}\right)}$ vs. $3.989752_{\left(37^{\circ} \mathrm{C}\right)}$ & -0.04366 & $\mathrm{C}_{5 \mathrm{~A}} \mathrm{C}_{4 \mathrm{~A}}$ & $1.8_{\left(22^{\circ} \mathrm{C}\right)}$ vs. $3.989752_{\left(37^{\circ} \mathrm{C}\right)}$ & -0.04366 \\
\hline $\mathrm{O}_{1} \mathrm{C}_{5}$ & $0.00055_{\left(22^{\circ} \mathrm{C}\right)}$ vs. $0.000602_{\left(37^{\circ} \mathrm{C}\right)}$ & -0.04158 & $\mathrm{O}_{1 \mathrm{~A}} \mathrm{C}_{5 \mathrm{~A}}$ & $0.00055_{\left(22^{\circ} \mathrm{C}\right)}$ vs. $0.000802_{\left(37^{\circ} \mathrm{C}\right)}$ & -0.04158 \\
\hline $\mathrm{O}_{2} \mathrm{O}_{1}$ & $0.12_{\left(22^{\circ} \mathrm{C}\right)}$ vs. $0.424824_{\left(37^{\circ} \mathrm{C}\right)}$ & -0.08158 & $\mathrm{O}_{2 \mathrm{~A}} \mathrm{O}_{1 \mathrm{~A}}$ & $0.1651_{\left(22^{\circ} \mathrm{C}\right)}$ vs. $0.24445_{\left(37^{\circ} \mathrm{C}\right)}$ & -0.08158 \\
\hline $\mathrm{C}_{4} \mathrm{C}_{3}$ & $1.2_{\left(22^{\circ} \mathrm{C}\right)}$ vs. $2.2045401_{\left(37^{\circ} \mathrm{C}\right)}$ & -0.00166 & $\mathrm{C}_{4 \mathrm{~A}} \mathrm{C}_{3 \mathrm{~A}}$ & $1.2_{\left(22^{\circ} \mathrm{C}\right)}$ Vs. $3.142763_{\left(37^{\circ} \mathrm{C}\right)}$ & -0.00166 \\
\hline $\mathrm{C}_{3} \mathrm{C}_{2}$ & $0.6_{\left(22^{\circ} \mathrm{C}\right)}$ vs. $0.889337_{\left(37^{\circ} \mathrm{C}\right)}$ & -0.00166 & $\mathrm{C}_{3 \mathrm{~A}} \mathrm{C}_{2 \mathrm{~A}}$ & 0.6 vs. $1.957876_{\left(37^{\circ} \mathrm{C}\right)}$ & -0.00166 \\
\hline $\mathrm{C}_{2} \mathrm{C}_{1}$ & $0.00001_{\left(22^{\circ} \mathrm{C}\right)}$ vs. $0.000015_{\left(37^{\circ} \mathrm{C}\right)}$ & -0.07966 & $\mathrm{C}_{2 \mathrm{~A}} \mathrm{C}_{1 \mathrm{~A}}$ & 0.00001 vs. $0.000033_{\left(37^{\circ} \mathrm{C}\right)}$ & -0.07966 \\
\hline $\mathrm{I}_{1} \mathrm{I}_{2}$ & $0.011_{\left(22^{\circ} \mathrm{C}\right)}$ vs. $0.020208_{\left(37^{\circ} \mathrm{C}\right)}$ & 0.146 & $\mathrm{I}_{1 \mathrm{~A}} \mathrm{I}_{2 \mathrm{~A}}$ & 0.011 vs. $0.01446_{\left(37^{\circ} \mathrm{C}\right)}$ & $0.155_{\left(22^{\circ} \mathrm{C}\right)}$ vs. $0.148_{\left(37^{\circ} \mathrm{C}\right)}$ \\
\hline $\mathrm{I}_{2} \mathrm{I}_{3}$ & $0.011_{\left(22^{\circ} \mathrm{C}\right)}$ vs. $0.01446_{\left(37^{\circ} \mathrm{C}\right)}$ & $0.049_{\left(22^{\circ} \mathrm{C}\right)}$ vs. $0.0265_{\left(37^{\circ} \mathrm{C}\right)}$ & $\mathrm{I}_{2 \mathrm{~A}} \mathrm{I}_{3 \mathrm{~A}}$ & 0.011 vs. $0.020208_{\left(37^{\circ} \mathrm{C}\right)}$ & $0.059_{\left(22^{\circ} \mathrm{C}\right)}$ vs. $0.009_{\left(37^{\circ} \mathrm{C}\right)}$ \\
\hline $\mathrm{I}_{3} \mathrm{I}_{4}$ & $0.00011_{\left(22^{\circ} \mathrm{C}\right)}$ vs. $0.000335_{\left(37^{\circ} \mathrm{C}\right)}$ & $0.002_{\left(22^{\circ} \mathrm{C}\right)}$ vs. $0.001_{\left(37^{\circ} \mathrm{C}\right)}$ & $\mathrm{I}_{3 \mathrm{~A}} \mathrm{I}_{4 \mathrm{~A}}$ & 0.00011 vs. $0.000335_{\left(37^{\circ} \mathrm{C}\right)}$ & $0.005_{\left(22^{\circ} \mathrm{C}\right)}$ vs. $0.001_{\left(37^{\circ} \mathrm{C}\right)}$ \\
\hline $\mathrm{I}_{4} \mathrm{I}_{5}$ & $0.0128_{\left(22^{\circ} \mathrm{C}\right)}$ vs. $0.018973_{\left(37^{\circ} \mathrm{C}\right)}$ & 0.001 & $\mathrm{I}_{4 \mathrm{~A}} \mathrm{I}_{5 \mathrm{~A}}$ & 0.01392 vs. $0.020633_{\left(37^{\circ} \mathrm{C}\right)}$ & 0.001 \\
\hline $\mathrm{I}_{5} \mathrm{I}_{\mathrm{O} 1}$ & $0.068188_{\left(22^{\circ} \mathrm{C}\right)}$ vs. $0.078668_{\left(37^{\circ} \mathrm{C}\right)}$ & 0.001 & $\mathrm{I}_{5 \mathrm{~A}} \mathrm{I}_{\mathrm{O} 1 \mathrm{~A}}$ & 0.07127 vs. $0.130931_{\left(37^{\circ} \mathrm{C}\right)}$ & 0.001 \\
\hline $\mathrm{I}_{\mathrm{O} 1} \mathrm{I}_{\mathrm{O} 2}$ & $0.073695_{\left(22^{\circ} \mathrm{C}\right)}$ vs. $0.085021_{\left(37^{\circ} \mathrm{C}\right)}$ & 0.00071547 & $\mathrm{I}_{\mathrm{O} 1 \mathrm{~A}} \mathrm{I}_{\mathrm{O} 2 \mathrm{~A}}$ & 0.1126 & 0.00071547 \\
\hline $\mathrm{I}_{\mathrm{O} 2} \mathrm{I}_{\mathrm{O} 1}$ & $0.83054_{\left(22^{\circ} \mathrm{C}\right)}$ vs. $2.448496_{\left(37^{\circ} \mathrm{C}\right)}$ & -0.08158 & $\mathrm{I}_{\mathrm{O} 2 \mathrm{~A}} \mathrm{I}_{\mathrm{O} 1 \mathrm{~A}}$ & 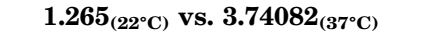 & -0.08158 \\
\hline $\mathrm{I}_{\mathrm{O} 1} \mathrm{I}_{5}$ & $0.069357_{\left(22^{\circ} \mathrm{C}\right)}$ vs. $0.129264_{\left(37^{\circ} \mathrm{C}\right)}$ & -0.04158 & $\mathrm{I}_{\mathrm{O} 1 \mathrm{~A}} \mathrm{I}_{5 \mathrm{~A}}$ & $0.079857_{\left(22^{\circ} \mathrm{C}\right)}$ vs. $00.173907_{\left(37^{\circ} \mathrm{C}\right)}$ & -0.04158 \\
\hline $\mathrm{I}_{5} \mathrm{I}_{4}$ & $0.061484_{\left(22^{\circ} \mathrm{C}\right)}$ vs. $0.09195_{\left(37^{\circ} \mathrm{C}\right)}$ & -0.04366 & $\mathrm{I}_{5 \mathrm{~A}} \mathrm{I}_{4 \mathrm{~A}}$ & $0.065484_{\left(22^{\circ} \mathrm{C}\right)}$ vs. $0.09195_{\left(37^{\circ} \mathrm{C}\right)}$ & -0.04366 \\
\hline $\mathrm{I}_{4} \mathrm{I}_{3}$ & $0.000042_{\left(22^{\circ} \mathrm{C}\right)}$ vs. $0.000059_{\left(37^{\circ} \mathrm{C}\right)}$ & -0.00166 & $\mathrm{I}_{4 \mathrm{~A}} \mathrm{I}_{3 \mathrm{~A}}$ & $0.00035_{\left(22^{\circ} \mathrm{C}\right)}$ vs. $0.000524_{\left(37^{\circ} \mathrm{C}\right)}$ & -0.00166 \\
\hline $\mathrm{I}_{3} \mathrm{I}_{2}$ & $2.0 \mathrm{e}-9_{\left(22^{\circ} \mathrm{C}\right)}$ vs. $2.96446 \mathrm{E}-9_{\left(37^{\circ} \mathrm{C}\right)}$ & -0.00166 & $\mathrm{I}_{3 \mathrm{~A}} \mathrm{I}_{2 \mathrm{~A}}$ & $2.0 \mathrm{E}-9_{\left(22^{\circ} \mathrm{C}\right)}$ vs. $6.526254 \mathrm{E}-9_{\left(37^{\circ} \mathrm{C}\right)}$ & -0.00166 \\
\hline $\mathrm{I}_{2} \mathrm{I}_{1}$ & $2.0 \mathrm{e}-9_{\left(22^{\circ} \mathrm{C}\right)}$ vs. $2.96446 \mathrm{E}-9_{\left(37^{\circ} \mathrm{C}\right)}$ & -0.07966 & $\mathrm{I}_{2 \mathrm{~A}} \mathrm{I}_{1 \mathrm{~A}}$ & $2.0 \mathrm{E}-9_{\left(22^{\circ} \mathrm{C}\right)}$ vs. $6.526254 \mathrm{E}-9_{\left(37^{\circ} \mathrm{C}\right)}$ & -0.07966 \\
\hline $\mathrm{C}_{4} \mathrm{I}_{4}$ & $0.0232_{\left(22^{\circ} \mathrm{C}\right)}$ vs. $0.0106_{\left(37^{\circ} \mathrm{C}\right)}$ & 0.039942 & $\mathrm{C}_{4 \mathrm{~A}} \mathrm{I}_{4 \mathrm{~A}}$ & $0.03215_{\left(22^{\circ} \mathrm{C}\right)}$ vs. $0.0111_{\left(37^{\circ} \mathrm{C}\right)}$ & 0.0451 \\
\hline $\mathrm{C}_{5} \mathrm{I}_{5}$ & $0.0369_{\left(22^{\circ} \mathrm{C}\right)}$ vs. $0.025_{\left(37^{\circ} \mathrm{C}\right)}$ & 0.039942 & $\mathrm{C}_{5 \mathrm{~A}} \mathrm{I}_{5 \mathrm{~A}}$ & $0.0479_{\left(22^{\circ} \mathrm{C}\right)}$ Vs. $0.0285_{\left(37^{\circ} \mathrm{C}\right)}$ & 0.0451 \\
\hline $\mathrm{O}_{1} \mathrm{I}_{\mathrm{O} 1}$ & $0.492_{\left(22^{\circ} \mathrm{C}\right)}$ vs. $0.055_{\left(37^{\circ} \mathrm{C}\right)}$ & 0.039942 & $\mathrm{O}_{1 \mathrm{~A}} \mathrm{I}_{\mathrm{O} 1 \mathrm{~A}}$ & $0.492_{\left(22^{\circ} \mathrm{C}\right)}$ vs. $0.055_{\left(37^{\circ} \mathrm{C}\right)}$ & 0.0451 \\
\hline $\mathrm{O}_{2} \mathrm{I}_{\mathrm{O} 2}$ & $0.8_{\left(22^{\circ} \mathrm{C}\right)}$ vs. $0.2_{\left(37^{\circ} \mathrm{C}\right)}$ & 0.039942 & $\mathrm{O}_{2 \mathrm{~A}} \mathrm{I}_{\mathrm{O} 2 \mathrm{~A}}$ & $0.8_{\left(22^{\circ} \mathrm{C}\right)}$ vs. $0.2_{\left(37^{\circ} \mathrm{C}\right)}$ & 0.0451 \\
\hline $\mathrm{I}_{4} \mathrm{C}_{4}$ & $3.80 \mathrm{E}-5_{\left(22^{\circ} \mathrm{C}\right)}$ vs. $1.70889 \mathrm{e}-5_{\left(37^{\circ} \mathrm{C}\right)}$ & $-0.048_{\left(22^{\circ} \mathrm{C}\right)}$ vs. $-0.075_{\left(37^{\circ} \mathrm{C}\right)}$ & $\mathrm{I}_{4 \mathrm{~A}} \mathrm{C}_{4 \mathrm{~A}}$ & $3.75 \mathrm{E}-5_{\left(22^{\circ} \mathrm{C}\right)}$ vs. $4.9295 \mathrm{E}-5_{\left(37^{\circ} \mathrm{C}\right)}$ & $-0.048_{\left(22^{\circ} \mathrm{C}\right)}$ vs. $-0.075_{\left(37^{\circ} \mathrm{C}\right)}$ \\
\hline $\mathrm{I}_{5} \mathrm{C}_{5}$ & $3.80 \mathrm{E}-5_{\left(22^{\circ} \mathrm{C}\right)}$ vs. $1.70889 \mathrm{e}-5_{\left(37^{\circ} \mathrm{C}\right)}$ & $-0.048_{\left(22^{\circ} \mathrm{C}\right)}$ vs. $-0.075_{\left(37^{\circ} \mathrm{C}\right)}$ & $\mathrm{I}_{5 \mathrm{~A}} \mathrm{C}_{5 \mathrm{~A}}$ & $3.75 \mathrm{E}-5_{\left(22^{\circ} \mathrm{C}\right)}$ vs. $4.9295 \mathrm{E}-5_{\left(37^{\circ} \mathrm{C}\right)}$ & $-0.048_{\left(22^{\circ} \mathrm{C}\right)}$ vs. $-0.075_{\left(37^{\circ} \mathrm{C}\right)}$ \\
\hline $\mathrm{I}_{\mathrm{O} 1} \mathrm{O}_{1}$ & $3.80 \mathrm{E}-5_{\left(22^{\circ} \mathrm{C}\right)}$ vs. $1.70889 \mathrm{E}-5_{\left(37^{\circ} \mathrm{C}\right)}$ & $-0.048_{\left(22^{\circ} \mathrm{C}\right)}$ vs. $-0.075_{\left(37^{\circ} \mathrm{C}\right)}$ & $\mathrm{I}_{\mathrm{O} 1 \mathrm{~A}} \mathrm{O}_{1 \mathrm{~A}}$ & $3.75 \mathrm{E}-5_{\left(22^{\circ} \mathrm{C}\right)}$ vs. $4.9295 \mathrm{E}-5_{\left(37^{\circ} \mathrm{C}\right)}$ & $-0.048_{\left(22^{\circ} \mathrm{C}\right)}$ vs. $-0.075_{\left(37^{\circ} \mathrm{C}\right)}$ \\
\hline $\mathrm{I}_{\mathrm{O} 2} \mathrm{O}_{2}$ & $0.0001056_{\left(22^{\circ} \mathrm{C}\right)}$ vs. $0.000139_{\left(37^{\circ} \mathrm{C}\right)}$ & $-0.048_{\left(22^{\circ} \mathrm{C}\right)}$ vs. $-0.075_{\left(37^{\circ} \mathrm{C}\right)}$ & $\mathrm{I}_{\mathrm{O} 2 \mathrm{~A}} \mathrm{O}_{2 \mathrm{~A}}$ & $0.0001188_{\left(22^{\circ} \mathrm{C}\right)}$ vs. $0.0001562_{\left(37^{\circ} \mathrm{C}\right)}$ & $-0.048_{\left(22^{\circ} \mathrm{C}\right)}$ vs. $-0.075_{\left(37^{\circ} \mathrm{C}\right)}$ \\
\hline
\end{tabular}

inactivated state with a higher likelihood propensity to recover from inactivation via the silent route (e.g., $\mathrm{I}_{\mathrm{O} 1}$ in Fig. 8). Moreover, the inhibitory effect of AMD of the tail currents is stronger at $37^{\circ} \mathrm{C}$ by $\mathrm{AMD}$ (with a physiological pulse protocol; Fig. 7B), again making AMD a better antiarrhythmic for tachyarrhythmia at the body temperature because of the stronger prolongation effect on the repolarization phase (phase 3) in the cardiac action potential (see below). It is conceivable that AMD does not significantly jeopardize ion conduction, but deters the initial outward movement of the voltage sensors and the reopening of the C-type inactivation gate. The local electrical field is more condensed, however, so that the same movement of the voltage sensor now embodies a larger electrical energy change. The activation rate at mild depolarization is therefore slowed, but the activation as well as inactivation rates are more accelerated at stronger depolarization, by AMD. By the same token, AMD may also facilitate the silent route but slows the overall kinetics of recovery from inactivation with the altered electrical field and/or microenvironment of the voltage sensors and thus the electrical as well as nonelectrical energy changes associated with gating (see the gating scheme in Fig. 8).

The Unique Effect of AMD against Tachyarrhythmia: Different Use-Dependent and Temperature-Dependent Inhibition and Enhancement of hERG Currents at Different Phases of Cardiac Action Potentials. We have seen that the inhibition of hERG currents by AMD during the test and tail pulses is more pronounced and develops faster with more frequently repetitive pulses and higher temperature (Fig. 7). AMD therefore would necessitate less use or fewer

of choosing the resurgent route of recovery from $\mathrm{O}_{1}$. AMD not only increases channel activation/inactivation at moderate depolarization, but would also increase the relative proportion of $\mathrm{I}_{\mathrm{O} 2} \rightarrow \mathrm{I}_{\mathrm{O} 1} \rightarrow \mathrm{I}_{5}$ so that there are decreasing tail currents associated with increased inactivation. These major changes made by AMD are shown in red arrows. (B) Simulation of the currents elicited by $(-60,-30,0$, and $+30 \mathrm{mV})$ with short (300-ms) depolarization pulse (the same as that in Figs. 1 and 3). (C) Simulation of the currents with the same protocols in Fig. 4 . Note enhancement and inhibition of the currents in the initial activation phase by AMD at $22^{\circ} \mathrm{C}$ and $37^{\circ} \mathrm{C}$, respectively. (D) Simulation of the currents with the same protocols in Fig. 5. Note enhancement of the currents in the afterdepolarization (at $-60 \mathrm{mV}$ ) by AMD especially at $37^{\circ} \mathrm{C}$. 
repetitive plateau depolarization pulses at $37^{\circ} \mathrm{C}$ to achieve an adequate inhibition of hERG currents during the plateau depolarization (Sager et al., 1993). The inhibition of hERG tail currents by AMD also contributes to a prolonged repolarization phase following the depolarization and thus a slower and normalized heart rate. Most interestingly, if any perturbation of the membrane potential should happen during the repolarization phase and lead to premature depolarization (i.e., afterdepolarization), more hERG currents would be elicited to counteract the premature depolarization in the presence of AMD especially in a condition of tachycardia and especially at $37^{\circ} \mathrm{C}$ (i.e., use-dependent inhibition of hERG currents at the preceding plateau and use-dependent enhancement of hERG currents at the afterdepolarization; Fig. 7). AMD therefore is a unique pharmacological agent, effectively lengthening the plateau and repolarization phase of the cardiac action potential to ameliorate tachycardia on the one hand, and effectively protecting the repolarization phase from premature afterdepolarization on the other hand to assure low risk of tachyarrhythmia. The hallmark of type III antiarrhythmic agents is inhibition of the $\mathrm{K}^{+}$channels and thus prolongation of the QT interval, which has direct slowing effect on tachycardia. The inhibition of $\mathrm{K}^{+}$channels, however, increases the chances of early and delayed afterdepolarization and thus the possibilities of development of tachyarrhythmia. AMD therefore has its therapeutic and adverse effects both from prolongation of QT interval by inhibition of hERG currents, but the chances of adverse effect are markedly lowered because of enhancement of hERG currents during the afterdepolarization. It is of note that temperature has a critical action on the foregoing effect of AMD and also the molecular behaviors of the hERG channel themselves. In principle, lower temperatures or relevant pathophysiological/pharmacotherapeutic scenarios that slow or decrease hERG channel activation may readily jeopardize the unique afterdepolarization-preventing effect of AMD or even the essential physiologic function of hERG channels itself, and thus must be carefully handled with the foregoing rationales taken into consideration if encountered.

\section{Authorship Contributions}

Participated in research design: Lo, Kuo.

Conducted experiments: Lo.

Performed data analysis: Lo, Kuo.

Wrote or contributed to the writing of the manuscript: Lo, Kuo.

\section{References}

Babcock JJ and Li M (2013) hERG channel function: beyond long QT. Acta Pharmacol Sin 34:329-335.

Bett GC, Zhou Q, and Rasmusson RL (2011) Models of HERG gating. Biophys $J$ 101:631-642.

Catterall WA (2010) Ion channel voltage sensors: structure, function, and pathophysiology. Neuron 67:915-928.

Clancy CE and Rudy Y (2001) Cellular consequences of HERG mutations in the long QT syndrome: precursors to sudden cardiac death. Cardiovasc Res 50:301-313.

Cuello LG, Jogini V, Cortes DM, and Perozo E (2010) Structural mechanism of C-type inactivation in $\mathrm{K}(+)$ channels. Nature 466:203-208.

Furutani K, Yamakawa Y, Inanobe A, Iwata M, Ohno Y, and Kurachi Y (2011) A mechanism underlying compound-induced voltage shift in the current activation of hERG by antiarrhythmic agents. Biochem Biophys Res Commun 415:141-146.

Heger JJ, Prystowsky EN, Jackman WM, Naccarelli GV, Warfel KA, Rinkenberger RL, and Zipes DP (1981) Clinical efficacy and electrophysiology during long-term therapy for recurrent ventricular tachycardia or ventricular fibrillation. $N$ Engl J Med 305:539-545.

Jiang M, Dun W, Fan JS, and Tseng GN (1999) Use-dependent "agonist" effect of azimilide on the HERG channel. J Pharmacol Exp Ther 291:1324-1336.
Jiang M, Zhang M, Maslennikov IV, Liu J, Wu DM, Korolkova YV, Arseniev AS, Grishin EV, and Tseng GN (2005) Dynamic conformational changes of extracellular S5-P linkers in the hERG channel. J Physiol 569:75-89.

Johnson JP Jr, Mullins FM, and Bennett PB (1999) Human ether-à-go-go-related gene $\mathrm{K}^{+}$channel gating probed with extracellular $\mathrm{ca}^{2+}$ : evidence for two distinct voltage sensors. J Gen Physiol 113:565-580.

Kauthale RR, Dadarkar SS, Husain R, Karande VV, and Gatne MM (2015) Assessment of temperature-induced hERG channel blockade variation by drugs. J Appl Toxicol 35:799-805.

Kiehn J, Thomas D, Karle CA, Schöls W, and Kübler W (1999) Inhibitory effects of the class III antiarrhythmic drug amiodarone on cloned HERG potassium channels. Naunyn Schmiedebergs Arch Pharmacol 359:212-219.

Kuo CC, Chen WY, and Yang YC (2004) Block of tetrodotoxin-resistant $\mathrm{Na}^{+}$channel pore by multivalent cations: gating modification and $\mathrm{Na}^{+}$flow dependence. J Gen Physiol 124:27-42.

Liu Y, Jurman ME, and Yellen G (1996) Dynamic rearrangement of the outer mouth of a $\mathrm{K}^{+}$channel during gating. Neuron 16:859-867.

Lu Y, Mahaut-Smith MP, Varghese A, Huang CL, Kemp PR, and Vandenberg JI (2001) Effects of premature stimulation on HERG $\mathrm{K}^{(+)}$channels. J Physiol 537:843-851.

Luo CH and Rudy Y (1994) A dynamic model of the cardiac ventricular action potential. I. Simulations of ionic currents and concentration changes. Circ Res 74: 1071-1096.

McPate MJ, Duncan RS, Hancox JC, and Witchel HJ (2008) Pharmacology of the short QT syndrome N588K-hERG $\mathrm{K}^{+}$channel mutation: differential impact on selected class I and class III antiarrhythmic drugs. Br J Pharmacol 155:957-966.

Milnes JT, Crociani O, Arcangeli A, Hancox JC, and Witchel HJ (2003) Blockade of HERG potassium currents by fluvoxamine: incomplete attenuation by $\mathrm{S} 6$ mutations at F656 or Y652. Br J Pharmacol 139:887-898.

Mitcheson JS (2003) Drug binding to HERG channels: evidence for a "non-aromatic" binding site for fluvoxamine. Br J Pharmacol 139:883-884.

Mitcheson JS, Chen J, Lin M, Culberson C, and Sanguinetti MC (2000) A structural basis for drug-induced long QT syndrome. Proc Natl Acad Sci USA 97:12329-12333.

Perry MD, Ng CA, and Vandenberg JI (2013) Pore helices play a dynamic role as integrators of domain motion during Kv11.1 channel inactivation gating. $J$ Biol Chem 288:11482-11491.

Ridley JM, Milnes JT, Witchel HJ, and Hancox JC (2004) High affinity HERG $\mathrm{K}^{(+)}$ channel blockade by the antiarrhythmic agent dronedarone: resistance to mutations of the S6 residues Y652 and F656. Biochem Biophys Res Commun 325 883-891.

Roden DM (2004) Drug-induced prolongation of the QT interval. N Engl J Med 350: $1013-1022$

Sager PT, Uppal P, Follmer C, Antimisiaris M, Pruitt C, and Singh BN (1993) Frequency-dependent electrophysiologic effects of amiodarone in humans. Circulation 88:1063-1071.

Sanguinetti MC, Jiang C, Curran ME, and Keating MT (1995) A mechanistic link between an inherited and an acquired cardiac arrhythmia: HERG encodes the IKr potassium channel. Cell 81:299-307.

Schönherr R and Heinemann SH (1996) Molecular determinants for activation and inactivation of HERG, a human inward rectifier potassium channel. J Physiol 493 635-642.

Smith PL, Baukrowitz T, and Yellen G (1996) The inward rectification mechanism of the HERG cardiac potassium channel. Nature 379:833-836.

Torres AM, Bansal PS, Sunde M, Clarke CE, Bursill JA, Smith DJ, Bauskin A, Breit SN, Campbell TJ, Alewood PF, et al. (2003) Structure of the HERG K ${ }^{+}$channel S5P extracellular linker: role of an amphipathic alpha-helix in C-type inactivation. $J$ Biol Chem 278:42136-42148.

Trudeau MC, Warmke JW, Ganetzky B, and Robertson GA (1995) HERG, a human inward rectifier in the voltage-gated potassium channel family. Science 269:92-95.

Vandenberg JI, Torres AM, Campbell TJ, and Kuchel PW (2004) The HERG K ${ }^{+}$ channel: progress in understanding the molecular basis of its unusual gating kinetics. Eur Biophys J 33:89-97.

Wang S, Liu S, Morales MJ, Strauss HC, and Rasmusson RL (1997) A quantitative analysis of the activation and inactivation kinetics of HERG expressed in Xenopus oocytes. J Physiol 502:45-60.

Yang YC, Hsieh JY, and Kuo CC (2009) The external pore loop interacts with S6 and S3-S4 linker in domain 4 to assume an essential role in gating control and anticonvulsant action in the $\mathrm{Na}^{(+)}$channel. J Gen Physiol 134:95-113.

Yang YC and Kuo CC (2002) Inhibition of $\mathrm{Na}^{(+)}$current by imipramine and related compounds: different binding kinetics as an inactivation stabilizer and as an open channel blocker. Mol Pharmacol 62:1228-1237.

Yang YC and Kuo CC (2005) An inactivation stabilizer of the $\mathrm{Na}+$ channel acts as an opportunistic pore blocker modulated by external $\mathrm{Na}^{+}$. J Gen Physiol 125:465-481.

Zhang M, Liu J, and Tseng GN (2004) Gating charges in the activation and inactivation processes of the HERG channel. J Gen Physiol 124:703-718.

Zhang Y, Colenso CK, El Harchi A, Cheng H, Witchel HJ, Dempsey CE, and Hancox JC (2016) Interactions between amiodarone and the hERG potassium channel pore determined with mutagenesis and in silico docking. Biochem Pharmacol 113 $24-35$

Zimetbaum P (2007) Amiodarone for atrial fibrillation. N Engl J Med 356:935-941.

Address correspondence to: Dr. Chung-Chin Kuo, National Taiwan University College of Medicine, No. 1 Jen-Ai Road, 1st Section, Taipei 100, Taiwan. E-mail: chungchinkuo@ntu.edu.tw 